\title{
Adaptive multicomponent nanocomposite coatings in surface engineering
}

\author{
A D Pogrebnjak, A A Bagdasaryan, A Pshyk, K Dyadyura
}

DOI: https://doi.org/10.3367/UFNe.2016.12.038018

\section{Contents}

1. Introduction

2. Principles of formation and tribo-mechanical properties of nanocomposite coatings

2.1 Basic physical principle underlying the formation of the nanostructural state; 2.2 Adaptive behavior of nanocomposite coatings under friction

3. Extensive studies of tribotechnical coatings

3.1 Coatings with the adaptive friction mechanism; 2.3 Multicomponent and multilayer nanocomposite coatings

4. Conclusion

\begin{abstract}
This paper reviews experimental research on nanocomposite protective coatings of various chemical compositions and structure. For adaptive multielement and multilayer systems with specific phase composition, structure, substructure, stress state, and high functional properties, formation conditions are considered; the behavior of such systems under extreme operating conditions and in tribological applications is examined; the structural, phase, and chemical composition are discussed as well as the hardness, friction and wear at elevated temperatures; and the adhesive strength of hierarchical protective coatings is analyzed. Finally, the adaptive behavior under different tribological test conditions of multifunctional, multilayer coatings as a function of their properties and structure is examined.
\end{abstract}

Keywords: nanostructured state, entropy, hierarchical adaptive coatings, friction, wear, adhesion strength

\section{Introduction}

An important trend in the development of nanotechnologies and new nanostructural materials is inextricably bound up

\footnotetext{
A D Pogrebnjak, A A Bagdasaryan, K Dyadyura Sumy State University, ul. Rimskogo-Korsakova 2, 40007 Sumy, Ukraine

E-mail: a.d.pogrebnjak@gmail.com,alexp@i.ua,artemsumdu@ukr.net, dyadyura.kostya@mail.ru

A Pshyk Sumy State University,

ul. Rimskogo-Korsakova 2, 40007 Sumy, Ukraine;

NanoBioMedical Centre, Adam Mickiewicz University,

Umultowska 85, 61-614 Poznań, Poland

E-mail: a.v.pshys@gmail.com

Received 10 May 2016, revised 30 November 2016 Uspekhi Fizicheskikh Nauk 187 (6) 629-652 (2017) DOI: https://doi.org/10.3367/UFNr.2016.12.038018 Translated by Yu V Morozov; edited by A Radzig
}

with investigations into the basic mechanisms of their synthesis, phase and structural states, and the physicomechanical properties of nanocomposite multicomponent protective coatings of various chemical compositions and internal architecture.

Modern nanocomposite multicomponent protective coatings are adaptive hierarchical materials consisting of alternating nanolayers of various modulated chemical compositions. These materials constitute complicated nonequilibrium systems in which nonlinear processes proceed, including those with bifurcations and generation of dissipative structures with phase transitions [1] and promoting the formation of nanocrystalline and/or nanocluster structures exhibiting unique functional properties [1-7]. Such processes are described in terms of physical mesomechanics [8] and nonequilibrium thermodynamics [1].

The functional properties of the coatings being considered, as of many others, are in the first place determined by grain size and shape, chemical and phase composition, crystallographic orientation, lattice structure, internal stress, etc. The most important line of nanomaterial research is the elucidation of the size dependence of their mechanical characteristics, such as hardness, plasticity, and elasticity. Current ideas on the suppression of incipient crack growth and the generation and propagation of dislocations associated with a reduction of crystallite size to below $10 \mathrm{~nm}$ in the absence of an anomalous Hall-Petch dependence characteristic of nanostructural materials find wide application in the development of new methods for the targeted synthesis of tailor-made coatings, providing thermal stability of their structures and physico-mechanical properties.

The results of basic research and simulation of physical regularities inherent to nanocrystalline films and coatings have been reported in numerous publications [9-38]. Nowadays, a variety of methods are available to prepare nanocomposite coatings $[1,4,6]$, including the inclusion of doping elements into a growing condensate and/or its ion bombard- 
ment. The structure and phase composition of a coating are controlled by combining various deposition regimes, by altering dopant concentrations, the partial pressure of the working gaseous mixture, and the substrate temperature, and by applying a negative bias potential to the substrate or bombarding it with high-energy gaseous ions.

A desired nanostructure is formed by thermodynamically controlled decomposition of the metastable or hypothetically homogeneous mixed phase of a solid solution. Such decomposition may proceed either through grain nucleation and growth or by the spinodal decomposition mechanism $[1,4,7$, 39-42]. It is important to note that the formation of a highly thermostable nanostructure implies high chemical activity of the system needed to maintain the thermodynamic driving force for phase segregation and a sufficiently high temperature $(770-870 \mathrm{~K})$ to ensure rapid diffusion for completing segregation during growth.

Of practical significance are innovative technologies for the synthesis of materials with a nanocrystalline structure, excellent physico-mechanical and operational properties by a goal-oriented choice of deposition technological parameters based on the known physical principles behind the achievement of a nanostructural state in the vacuum-plasma multicomponent and multilayer systems. Formulating conditions for manufacturing nanocomposite coatings and surface layers of materials with the desired specific properties would be expected to enhance the efficiency of the available equipment. Sufficiently fast deposition of coatings onto highly homogeneous large-area substrates under the influence of a multicomponent metallic plasma fluxes will be the primary way of implementing these strategies to decline energy consumption and reduce spraying costs.

This review deals with the physical aspects of designing multicomponent and multilayer nanostructures, which are based on hypotheses and ideas from various branches of natural sciences, including solid state and plasma physics, materials engineering, physical chemistry, condensed matter and consolidated material physics. Special attention is devoted to nanoscale multilayer nanocomposite coatings, bearing in mind some of their special physical, chemical, and micromechanical characteristics, such as high-temperature hardness and improved protective and heat-shielding properties, that make these materials most suitable for tribological applications under extreme conditions. The analysis is based on various coatings containing transition metals (Ti, Y, Hf, $\mathrm{Zr}, \mathrm{V}, \mathrm{Nb}, \mathrm{Ta}, \mathrm{Cr}, \mathrm{Al}, \mathrm{Mo}$ ) and nonmetal dopants (B, N, Si), with the particular emphasis put on the results of those studies that clarify the relationship between the structural-phase state and operational properties of the coatings of interest and the methods and conditions of their production [43-46].

Other issues addressed in the review include approaches to the development of adaptive composite coatings with a low friction coefficient. Considerable progress has been achieved over the past decade in improving adaptive thin-film coatings having low friction and wear coefficients within a broad range of working media, temperatures, and bearing stresses with a particular emphasis placed on the structural and antifrictional properties of ceramic matrices with noble metal nanocrystalline inclusions ( $\mathrm{TiC}-\mathrm{Ag}, \mathrm{YSZ}-\mathrm{Ag}, \mathrm{Ta}_{2} / \mathrm{Cr}_{2} \mathrm{AlC}-\mathrm{Ag}$, $\mathrm{CrAlN}-\mathrm{Ag}, \mathrm{Mo}_{2} \mathrm{~N}-\mathrm{Ag}$, and $\mathrm{MoCN}-\mathrm{Ag}$ (YSZ - yttria-stabilized zirconia)) [47-63].

These data are borrowed from articles published in the last 10 years and original work of the authors. Special emphasis is placed on the relationship between the struc- tural-phase state and functional properties of nanostructural and nanocomposite coatings. This review is intended to discuss the possibility of, strategies for, and objectives regarding development and application of nanocomposite multicomponent protective coatings of various chemical compositions.

\section{Principles of formation and tribo-mechanical properties of nanocomposite coatings}

Results of materials science research into protective coatings published in recent decades suggest the possibility of obtaining new materials with improved functional characteristics by means of structural and chemical engineering, such as nanostructural nanocomposite films and coatings, in particular, based on nitrides.

Nanocomposite coatings are materials consisting of a small amount of nanocrystals distributed in the amorphous matrix (Fig. 1). Both theoretical and experimental studies showed that the optimal thickness of an amorphous interlayer separating nanocrystallites is $1-3 \mathrm{~mm}$. It must contain a few monolayers. The formation of a nanocomposite structure occurs via segregation of one phase at the grain boundaries of another phase. This effect hampers grain growth and promotes the formation of the nanostructure. Taken together, the small grain size $(\leqslant 10 \mathrm{~nm})$ and the crucial role played by grain boundaries are responsible for improved and even totally new properties of nanocomposite materials, as opposed to bulk materials composed of grains $\geqslant 100 \mathrm{~nm}$ in size. The use of a large variety of borides, nitrides, carbides, and oxides (Fig. 1b) for the formation of nanocrystals with a ceramic, metallic, or carbonic amorphous matrix allows creating unique nanocomposite materials [64-69].

Nanostructural materials are developed based on the multilevel approach, i.e., using a multilevel strained solid model. In the framework of the synergetic methodology, a strained solid body is regarded as an open system highly nonequilibrium in local zones of stress concentrators undergoing local nonequilibrium structural transformations under the loading effects. These changes occur at different scale levels and differ in character, energy, rate, and bulk extension. Their self-organization under the given loading boundary conditions governs the formation of dissipative structures.

From the physical standpoint, transition to a nanostate is related to the manifestation of dimensional effects in its physico-mechanical properties [1, 4-6]. Experimental and theoretical studies on small particle thermodynamics give
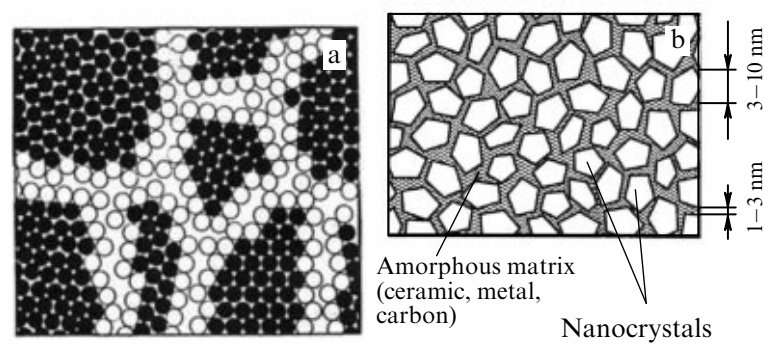

(borides, carbides, nitrides, oxides)

Figure 1. (a) Two-dimensional model of a nanocrystalline material (borrowed from Ref. [1]). (b) Schematic structure of a nanocomposite (from Ref. [13]). 
evidence that the particle size is an active variable influencing, together with other thermodynamic parameters, the state of the system and its reactivity. H Gleiter [70] defined the dimensional effect as the behavior of a material in which the size of the building blocks of the microstructure coincides with a certain critical length characterizing this phenomenon (the electron and phonon mean free paths, the size of magnetic domains, the critical radius of the dislocation loop, etc.).

The size dependence allows nanomaterials to be classified in terms of the geometric shape and dimension of constituent structural elements. Based on their size, nanomaterials are divided into the following main types: cluster materials, fibrous materials, films and multilayer structures, and bulk polycrystalline materials composed of nanoscale grains in all three directions [1]. A special class of nanostructures is distinguished, so-called nanocomposites having a heterogeneous structure formed by practically noninteracting phases with the mean linear dimensions of the structural elements below $100 \mathrm{~nm}[4,6]$.

An analysis of the available experimental data shows that the properties of nanomaterials depend not only on the size of structural elements but also on their environment, including the structural and phase state of interfaces (grain boundaries) [4].

The nature of interfaces, especially in nanomaterials, remains to be elucidated [15]. The simplest nanocrystalline material consisting of identical atoms contains two components with differed structures: grains of regular but various structures 5-20 $\mathrm{nm}$ in size (crystallites), and intercrystallite interfaces measuring up to $1.0 \mathrm{~nm}$. As a rule, such structural elements are an amorphous matrix and nanocrystalline phase inclusions (Fig. 1b).

Structural dimensional effects manifest themselves as variation of interatomic distances and rearrangement of the crystal structure up to the transition into the amorphous state. Chemical dimensional effects result in a change in the phase composition and reactivity of matter, which means that nanoparticles can be involved in reactions that fail to occur in the presence of substances in the compact state.

Most polycrystalline materials become harder and have their elastic limit enhanced as the mean size of crystallites decreases (the Hall-Petch law): in this way, mechanical dimensional effects manifest themselves. Certain physical dimensional effects are especially striking, e.g., reduced melting temperature of nanomaterials compared with bulk materials due to increased surface energy or a sharp change in electrophysical and magnetic properties.

A specific feature of nanomaterials is the enlargement of the volume fraction of interfaces with decreasing grain or crystallite size. They have nonequilibrium grain boundaries due to the high density of boundary defects. Such a departure from equilibrium is associated with an excess boundary energy and long-range elastic stress. Grain boundaries have a crystallographically regular structure, while grain boundary dislocations and their complexes serve as sources of elastic fields. Departure from equilibrium of grain boundaries results in high stresses and distortions in the crystal lattice, changes in interatomic distances and atom displacements up to the loss of long-range order. Despite a large number of experimental studies, the structure and properties of the intercrystallite layer remain unclear. Most authors maintain that its density differs from that of a crystal grain. Advocates of the amorphous grain-boundary cement hypothesis argue that the interlayers must have a lower density than the grains.
The size dependence of the activity of the particles involved in the reaction may be related to a change in their properties during interaction with an adsorbed reactant, correlation between the geometric structure and the structure of the electron shell, and to the symmetry of boundary orbitals of a metal particle with respect to adsorbed molecule orbitals.

The concept of multilayer architecture of coatings appears to be the most promising among the currently considered principles providing the basis for the creation of coatings for different purposes, because such structures meet a variety of requirements, even conflicting ones. It is proposed to use multicomponent compositions to ensure simultaneous nucleation of the islets of mutually insoluble or poorly soluble phases limiting the growth of nucleation centers. Plastic phases must be present in the coating composition to support relaxation of internal stresses and suppression of incipient crack growth. The multilayer organization makes it possible to develop coatings including both metastable and multicomponent materials in a single geometric body and thereby combine opposite concepts of individual layers in a multilayer coating (Fig. 2).

In accordance with the proposed principles of designing coatings, the method for predicting their composition consists in the choice of elements that guarantee the multiphase character of coatings under conditions of their synthesis, generation of phases with identical volume content (and, consequently, minimal difference between the probabilities of islet formation), and possibility of relaxation of stress concentrators at the boundaries of their conjugation.

Each layer of a multilayer composite coating may have either a monolayer (microstructuring) or multilayer (nanostructuring) organization. At present, the development of upto-date composite and multilayer types of coatings is based on the following main concepts:

- strengthening solid solutions,

- layers graded by bond types,

- metastable systems with a homogeneous metalloid structure,

- nanostructured multiphase layers,

- supermultilayer coatings with layers of nanometersized thicknesses.

The layered architecture of nanocoatings permits stabilizing (fixing) the given texture of each layer and creating materials for new types of coatings. The nanostructured multilayer coatings can be categorized into the following groups:

- standard wear-resistant coatings having a multilayer organization from materials with similar structures and chemical bonds,

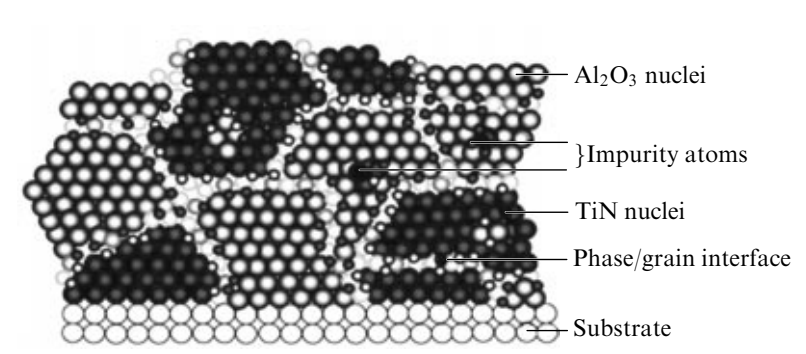

Figure 2. Models of the formation of nanocomposite multielement coatings. Microstructure self-organization at the stage of nucleation of mutually insoluble phases (from Ref. [1]). 


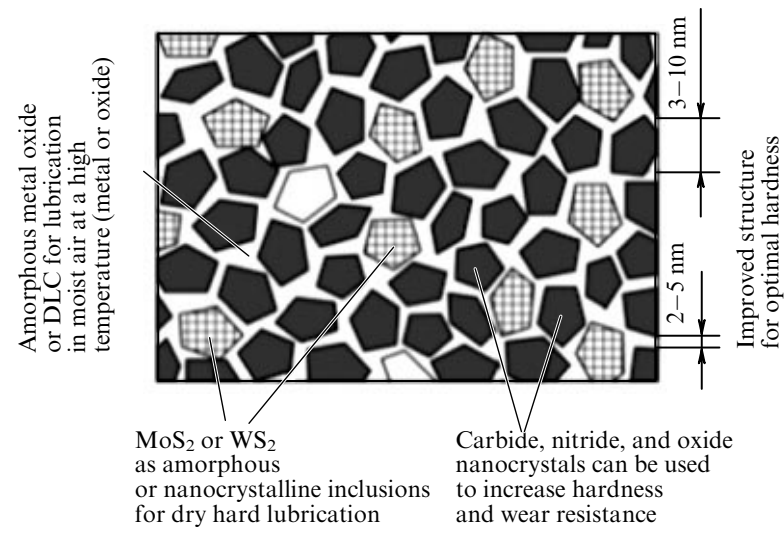

Figure 3. Schematic conceptual design of nanocomposite coatings with a 'chameleon' tribologically adaptive surface; DLC — diamond-like carbon films (from Refs [56, 59]).

- multilayer coatings from materials with significantly different structures and chemical bonds,

- multilayer coatings having layers with internal intermediate boundary sublayers of nanometer-sized thicknesses.

Multilayer coatings with nanothick layers can be exploited to activate various energy absorption processes that may result, given the optimal coating architecture and structure, in the enhancement of their viscosity and strength with only an insignificant reduction in hardness (conforming, a balanced hardness-to-viscosity ratio).

In recent decades, the development and improvement of so-called 'intelligent (smart)' materials and systems have constituted one of the most promising areas of tribological materials research. The special feature of such materials lies in their ability to exhibit adaptive structural properties during operation.

Figure 3 presents schematically the structure of nanocomposite coatings with a 'chameleon' tribologically adaptive surface.

The temperature-specific adaptive behavior of the chameleon surface includes a complicated chemical, physical, and structural evolution of contact surfaces with a tendency toward self-adjustment for the creation of conditions with low friction and wear coefficients and the enhancement of adaptive capability. The following main strategies have been applied in the last several years [63]:

- lubricant diffusion into a temperature-activated metal surface,

— formation of lubricious oxide phases activated by environmental temperature,

- temperature- and strain-induced evolution of structures.

\subsection{Basic physical principle underlying the formation of a nanostructural state}

Basic structure refinement patterns are described in the literature in terms of the defect-deformation theory. In the fields of external impacts of any nature, solids undergo local breaking of translational invariance of the crystal structure manifested as various defects, such as vacancies and interstitial atoms, atomic-vacancy nanoclusters of different configurations, dislocations, disclinations, twins, meso- and macrostripes of localized strain, and cracks. All these defects but point ones originate from local structural or structural- phase transformations in hydrostatic tension zones of different scales [71]. After a thermal equilibrium is established, point defects (e.g., vacancies or nodes of the crystal lattice unoccupied by atoms) become the main defects in a material, with the maximum concentration of vacancies amounting to $10^{-4}-10^{-5}$. Linear (dislocation type) defects play an important role in the formation of the real crystalline structure of a material, because they cause characteristic displacements from the nodes of an ideal crystal lattice, and its elastic distortions strongly affect the properties of the crystal and the material at large.

It was shown in Ref. [72] that nanostructural state regions in a strongly nonequilibrium solid body can exist only amidst quasiamorphic interlayers with a positive Gibbs thermodynamic potential:

$$
F(v)=U-T S+p v-\sum_{i=1}^{n} \mu_{i} c_{i},
$$

where $U$ is the internal energy, $T$ is the temperature, $S$ is the entropy, $p$ is the pressure, $v$ is the molar volume, and $\mu_{i}$ is the chemical potential of the $i$ th element with concentration $c_{i}$.

Because regions where defects accumulate are formed in local hydrostatic tension zones, the molar volume $v$ serves as an independent argument when the Gibbs potential alters. Nonequilibrium thermodynamics allow considering the structure of a deformable solid body to be a system of mesosubstructures of different scales. The formation of metastable meso-substructures at different scale levels in a crystal gives rise to local periodic minima in the curve describing the dependence of the Gibbs thermodynamic potential $F$ on the molar volume $v$ (Fig. 4) [72].

In a crystal residing in the equilibrium state, the Gibbs thermodynamic potential $F\left(v_{0}\right)$ at $v=v_{0}$ has a minimal value. Any change in $v$ in the external field is accompanied by a rise in the internal energy $U$ and, therefore, in $F(v)$. The appearance of local minima in the ascending branch of the $F(v, \alpha)$ curve is related to entropy production and redistribution of doping elements between the initial crystal and the defective phase due to the difference between the chemical

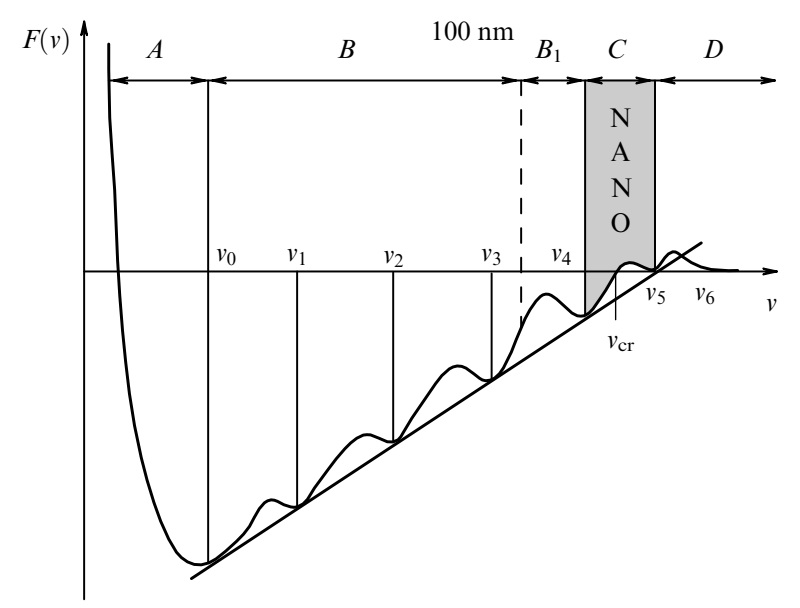

Figure 4. Gibbs thermodynamic potential $F$ plotted versus molar volume $v$ and taking account of local hydrostatic tension zones of different scales in which defective structures arise: $A-$ hydrostatic compression, $B-$ mesosubstructures at different structural scale levels, $B_{1}$ - nano-scale structures, $C$ - nano-scale states, $D$ - porosity and failure, $v_{\mathrm{cr}}$ - critical molar volume of the local hydrostatic compression zone (from Ref. [72]). 
potentials $\mu_{i}$ of each $i$ th component (here, $\alpha$ is the macroscopic phenomenological constant).

According to Ref. [72], the entropy production $\sigma_{S}$ is described by the relationship

$$
\sigma_{S}=\frac{\chi(\nabla T)^{2}}{T^{2}}+\rho \frac{v \sigma}{T}-\frac{\rho}{T^{2}}([\alpha v], \nabla T),
$$

where $\chi$ is the thermal conductivity, $\rho$ is the material density, $v$ is the molar volume proportional to the defect flux density, and $\sigma$ is the hydrostatic tension in the zone where the defective phase is formed.

Pre-transition two-phase nanostructural states (see Fig. 4) arise near the zero Gibbs thermodynamic potential when the molar volume in a crystal strongly departs from equilibrium one and falls in the $v_{4}-v_{5}$ range. Such states are characterized by an elevated concentration of structural vacancies, atomicvacancy nanoclusters of various configurations, and metastable phases.

The specificity of the thermodynamic state of nanostructural materials is attributable to the closeness of their Gibbs thermodynamic potential to zero and the appearance of pretransition quasiamorphic states responsible for the wellknown anomalous behavior of parameters of the Hall-Petch equation, when the grain size is $\leqslant 30 \mathrm{~nm}$. Such a structure exhibits high strength, wear resistance, and relaxation capability in response to external high-energy impacts. The appearance of the amorphous phase in a nanostructured film is, as a rule, accompanied by structural changes, such as transition from the columnar structure (an assembly of interrelated columns) to the composite structure in which nanocrystals of one or several phases are separated by thin amorphous interlayers. In this case, the amorphous component most closely conforms with the surface of nanocrystallites and secures good adhesion which promotes a significant increase of strength, while the excellent mechanical properties of the composite are due to a small size of the second phase combined with the high strength of intergrain boundaries.

The synergetic approach [73-75] makes it possible to present the thermodynamics and kinetics of self-organizing systems in the framework of a single paradigm. A major obstacle to combining synergetic and thermodynamic approaches is that the former implies that self-organization must decrease entropy as a measure of disorder, while the latter suggests that entropy must either increase or remain constant. This controversy is settled by taking into account that the self-organization process proceeds in an open (nonequilibrium) subsystem representing part of a closed system obeying the second law of thermodynamics. However, phase transitions demonstrate that thermodynamic transformations realized via self-organization are not necessarily reduced to ordering, i.e., a reduction in entropy (even in the broad sense of the word). On the other hand, the assumption of entropy reduction due to the open character of the subsystem does not clarify the self-organization mechanism.

As far as the process of kinetic self-organization is concerned, the strengthening of external action results in a decrease in stationary entropy, implying the onset of ordering. Self-organization leads to a metastable state corresponding to the minimum of synergetic potential (Fig. 5) in which the system may remain arbitrarily long till it experiences an external impact. A characteristic feature of the synergetic state is that it is stationary but not equilibrium one.

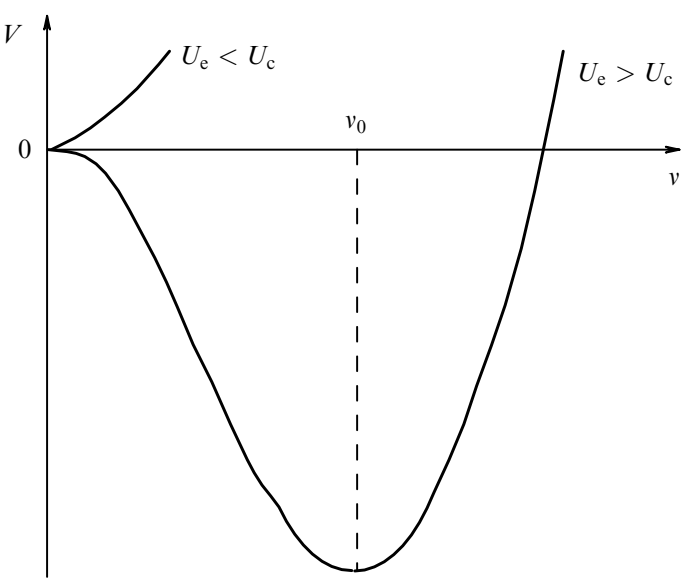

Figure 5. Synergetic potential versus order parameter for a second-order phase transition at different $U_{\mathrm{e}}$ values (from Ref. [76]).

Thus, it can be argued that two self-organization regimes are feasible, depending on conservation conditions. The thermodynamic regime is characterized by a spontaneous value of the internal parameter reduced to the density of the conserved quantity during transition to the closed system. The kinetic regime takes place in the absence of density conservation even for a closed system, when self-organization results in a spontaneous flux conjugate to this density. The former regime represents phase transition kinetics with a non-conserved order parameter. For the latter regime, the physical nature of the stationary kinetic state in which the flux retains a finite value remains unclear. This regime is usually considered based on the simplest Lorentz scheme. Such an approach leads to the standard relationships of thermodynamics and physical kinetics [74].

In the framework of the above representation, the selforganization process is parametrized by the following quantities: the internal parameter representing conserved density during transition to a closed subsystem; the conjugate field reduced to the gradient of the respective flux, and the governing parameter whose value is conditioned by an external impact and determines the state of the system [76].

In light of the adiabatic approximation, the above consideration indicates that the dissipative dynamics of a self-organizing system can be described by the Lorentz model in which variation of molar volume $v(\tau)$ plays the role of internal parameter $S$ reduced to entropy and representing the field conjugate to the internal parameter, while the internal energy $U$ is the governing parameter.

Suppose that the process of self-organization in such systems is represented by the Lorentz system of equations

$$
\begin{aligned}
& \dot{v}=-\frac{v}{\tau_{v}}+a_{v} S, \\
& \dot{S}=-\frac{S}{\tau_{S}}+a_{S} v U, \\
& \dot{U}=\frac{U_{\mathrm{e}}-U}{\tau_{U}}-a_{U} v S .
\end{aligned}
$$

The Lorentz system is a set of three differential equations that express the rates $\dot{v}, \dot{S}, \dot{U}$ of changes to $v, S, U$ through their values. A characteristic feature of these expressions is that they all contain dissipative terms inversely proportional to respective relaxation times $\tau_{v}, \tau_{S}, \tau_{U}$. In system (3), $a_{v}, a_{S}, a_{U}$ 
are positive coupling constants, and $U_{\mathrm{e}}$ is the external impact parameter. For the purpose of studying the thermodynamics of phase transitions, the adiabatic approximation $\tau_{S} \gg \tau_{U}, \tau_{v}$ is usually assumed, which implies that the conjugate field $S(\tau)$ and the governing parameter $U(\tau)$ change in the course of their evolution so quickly that they keep pace with slow variations of the order parameter $v(\tau)$ [76]. The evolution of the system is described by the Landau-Khalatnikov equation, in which the synergetic potential $V$ plays the role of free energy (see Fig. 5):

$$
V=\frac{v^{2}}{2}\left\{1-\frac{U_{\mathrm{e}}}{U_{\mathrm{c}}}\left(\frac{v}{v_{\max }}\right)^{-2} \ln \left[1+\left(\frac{v}{v_{\max }}\right)^{2}\right]\right\},
$$

where $U_{\mathrm{c}} \equiv\left(\alpha_{v} \alpha_{S}\right)^{-1}$ stands for the critical value.

The synergetic approach is based on the fact that positive feedback loop linking another pair of parameters $(v(\tau), U(\tau))$ and $S(\tau)$ leads to self-organization of the system representing the phase transition. The negative feedback loop linking the order parameter and the conjugate field, reflecting Le Chatelier's principle, lowers the stationary value of the governing parameter compared with its value fixed by the external impact. As a result, the synergetic approach reduces to the phenomenological scheme of phase transition.

Specific kinetic features of the phase transition deduced from model considerations [77] are easy to explain in terms of the synergetic approach by de-emphasizing the co-subordination principle on the assumption that the longest relaxation time is inherent in two, rather than one, hydrodynamic degrees of freedom. In this case, the phase transition is represented by a system of two differential equations, and the problem reduces to the analysis of possible scenarios of second- and first-order transformations. An important advantage of the synergetic approach is the possibility of taking into account the effect of the generalized Le Chatelier's principle, irrespective of narrow model considerations.

The authors of Refs [77-79] have assumed the existence of parameter $\alpha$ characterizing the degree of departure of a system from equilibrium. In nanostructured coatings, this parameter stands for the size of nanostructural components and is related to the density of crystal structure imperfections inside a coating layer, the number of which increases with decreasing the size of the nanocrystals. Due to this, smaller nanocrystals have higher values of parameter $\alpha$ [77]. Entropy production in this case is defined as

$$
\sum_{k} X_{k} J_{k}=\frac{1}{L}\left(\frac{\partial J}{\partial \alpha}\right)^{2}(\delta \alpha)^{2}
$$

where $X_{k}$ is the driving force, $J_{k}$ is the flow rate, and $L$ is the phenomenological or kinetic coefficients (any functions of the parameters of state, e.g., temperature, pressure, composition, etc.).

Equation (5) is a quadratic equation in which coefficient $L$ is unrelated to parameter $\alpha$, in agreement with the conclusion reached by Gershman and Bushe [87], who suggested that coefficients $L$ may depend on $\alpha$; as a result, the expression for excess entropy production takes the form

$$
\sum_{k} \delta X_{k} \delta J_{k}=\left[\frac{1}{L}\left(\frac{\partial J}{\partial \alpha}\right)^{2}-\frac{J}{L^{2}} \frac{\partial L}{\partial \alpha} \frac{\partial J}{\partial \alpha}\right](\delta \alpha)^{2} .
$$

The excess entropy production in Eqn (6) can be negative if $J / L^{2}(\partial L / \partial \alpha)(\partial J / \partial \alpha)$ is positive. To satisfy this condition, the derivatives $\partial J / \partial \alpha$ and $\partial L / \partial \alpha$ must have identical signs, either positive or negative.

Generalizing yields for a system with three independent nonlinear interrelated processes (three dissipation channels) the expression for excess entropy production:

$$
\begin{aligned}
\sum_{k} & \delta X_{k} \delta J_{k}=\left[\frac{\partial X_{1}}{\partial \alpha} \frac{\partial L_{1}}{\partial \alpha} X_{1}+L_{1}\left(\frac{\partial X_{1}}{\partial \alpha}\right)^{2}+\frac{\partial X_{1}}{\partial \alpha} \frac{\partial L_{12}}{\partial \alpha} X_{2}\right. \\
+ & L_{12} \frac{\partial X_{1}}{\partial \alpha} \frac{\partial X_{2}}{\partial \alpha}+\frac{\partial X_{1}}{\partial \alpha} \frac{\partial L_{13}}{\partial \alpha} X_{3}+L_{13} \frac{\partial X_{1}}{\partial \alpha} \frac{\partial X_{3}}{\partial \alpha} \\
+ & \frac{\partial X_{2}}{\partial \alpha} \frac{\partial L_{2}}{\partial \alpha} X_{2}+L_{2}\left(\frac{\partial X_{2}}{\partial \alpha}\right)^{2}+\frac{\partial X_{2}}{\partial \alpha} \frac{\partial L_{21}}{\partial \alpha} X_{1} \\
+ & L_{21} \frac{\partial X_{2}}{\partial \alpha} \frac{\partial X_{1}}{\partial \alpha}+\frac{\partial X_{2}}{\partial \alpha} \frac{\partial L_{23}}{\partial \alpha} X_{3}+L_{23} \frac{\partial X_{2}}{\partial \alpha} \frac{\partial X_{3}}{\partial \alpha} \\
+ & \frac{\partial X_{3}}{\partial \alpha} \frac{\partial L_{3}}{\partial \alpha} X_{3}+L_{3}\left(\frac{\partial X_{3}}{\partial \alpha}\right)^{2}+\frac{\partial X_{3}}{\partial \alpha} \frac{\partial L_{31}}{\partial \alpha} X_{1} \\
+ & \left.L_{31} \frac{\partial X_{3}}{\partial \alpha} \frac{\partial X_{1}}{\partial \alpha}+\frac{\partial X_{3}}{\partial \alpha} \frac{\partial L_{32}}{\partial \alpha} X_{2}+L_{32} \frac{\partial X_{3}}{\partial \alpha} \frac{\partial X_{2}}{\partial \alpha}\right](\delta \alpha)^{2} .
\end{aligned}
$$

In the case of a system of $n$ nonlinear processes, $2 n^{2}-n$ emerging stability conditions cannot be negative.

The probability of a loss of thermodynamic stability is given by the expression

$$
\frac{2 n^{2}-n}{2 n^{2}}=1-\frac{1}{2 n} \text {. }
$$

It follows from Eqn (6) that the probability of the loss of thermodynamic stability increases with the number of interrelated processes. This means that the probability of self-organization increases (a rise in the number of interrelated processes inside the system results in a higher number of interactions between these processes).

\subsection{Adaptive behavior of nanocomposite coatings under friction}

The thermodynamic aspects of the state of the surface layer of nanocomposite multicomponent coatings are of great theoretical and practical interest [80-89]. A variety of processes take place simultaneously on rubbing surfaces and in adjoining layers, the major ones being heat and matter fluxes, physicochemical interaction of the surfaces between themselves and with the environment, deformation, and structural and phase transformations in rubbing bodies, etc. As a rule, these processes are related to gradients of intense quantities originating from friction, such as temperature, chemical potential, and stress.

Other friction-associated processes proceed at temperatures rising due to frictional heating. These are largely phase transitions and chemical reactions operating at a given temperature in accordance with equilibrium diagrams of state. Heating may initiate processes driving the system into an equilibrium state if the structure of the material is initially nonequilibrium. Under such conditions, heating may induce relaxation processes with friction-independent driving forces. Chaotically directed flows are formed not only in friction zones but also in the adjacent layers. Therefore, the total entropy production in the system will be the sum of friction-produced entropy and the entropy of the corresponding fluxes [78].

The authors of Refs [78, 90-92] have formulated the principle of secondary dissipative heterogeneity, saying that 
the friction process facilitates structural adaptation of the contacting materials, resulting in the localization of all interactions within a thin-film object (a secondary structure, SS). According to this principle, an SS is needed to scatter energy as it passes from the friction zone into the rubbing bodies, and the energy scattering must occur at the minimal rate of entropy increment. Secondary structures perform protective functions by restricting the incidence of interactions inside the rubbing bodies and reducing the intensity of the interactions. Therefore, their appearance is consistent with Le Chatelier's principle [72].

It was shown in Refs [78, 90-92] that a change in entropy $(\mathrm{d} S)$ of a rubbing body under friction is the sum of several constituents:

$$
\mathrm{d} S=\mathrm{d} S_{\mathrm{i}}+\mathrm{d} S_{\mathrm{e}}+\mathrm{d} S_{\mathrm{m}}+\mathrm{d} S_{\mathrm{f}}-\mathrm{d} S_{\mathrm{w}},
$$

where $\mathrm{d} S_{\mathrm{i}}$ is the change in entropy without regard for transformations in surface layers (an increase in entropy by virtue of processes proceeding inside the system), $\mathrm{d} S_{\mathrm{e}}$ is the entropy flux without regard for mass transfer, $\mathrm{d} S_{\mathrm{m}}$ is the change in entropy at the expense of the intrinsic entropy of substances from the medium, $\mathrm{d} S_{\mathrm{f}}$ is the change in entropy due to interaction in the surface layer, and $\mathrm{d} S_{\mathrm{w}}$ is the change in entropy caused by wear, i.e., the removal of matter.

In the stationary state from expression (8), the rate of entropy change can be presented by the formula

$$
\frac{\mathrm{d} S_{\mathrm{w}}}{\mathrm{d} t}=\frac{\mathrm{d} S_{\mathrm{i}}}{\mathrm{d} t}+\frac{\mathrm{d} S_{\mathrm{e}}}{\mathrm{d} t}+\frac{\mathrm{d} S_{\mathrm{m}}}{\mathrm{d} t}+\frac{\mathrm{d} S_{\mathrm{f}}}{\mathrm{d} t},
$$

where $\mathrm{d} S_{\mathrm{i}} / \mathrm{d} t$ is entropy production, $\mathrm{d} S_{\mathrm{e}} / \mathrm{d} t$ is entropy flux, $\mathrm{d} S_{\mathrm{m}} / \mathrm{d} t$ is the rate of entropy change at the expense of the intrinsic entropy of substances from the medium, $\mathrm{d} S_{\mathrm{f}} / \mathrm{d} t$ is the rate of entropy change due to interactions in the surface layers, and $\mathrm{d} S_{\mathrm{w}} / \mathrm{d} t$ is the rate of entropy change caused by wear. In the case of cutting surfaces, equation (9) can be modified as follows:

$$
\frac{\mathrm{d} S_{\mathrm{w}}}{\mathrm{d} t}=\frac{\mathrm{d} S_{\mathrm{i}}}{\mathrm{d} t}+\frac{\mathrm{d} S_{\mathrm{e}}}{\mathrm{d} t}+\frac{\mathrm{d} S_{\mathrm{m}}}{\mathrm{d} t}-\frac{\mathrm{d} S_{\mathrm{f}}}{\mathrm{d} t} .
$$

The '-' sign indicates that wear products leave the body with their own entropy.

Quantity $\mathrm{d} S_{\mathrm{w}} / \mathrm{d} t$ characterizes wear product entropy. Entropy being an additive quantity, it can be argued that the smaller $\mathrm{d} S_{\mathrm{w}} / \mathrm{d} t$, the lower the wear intensity. This means that a reduction in entropy production decreases wear intensity. Unspontaneous surface processes $\mathrm{d} S_{\mathrm{f}} / \mathrm{d} t<0$ can (all other things being equal) reduce wear intensity.

A change in the entropy of matter flux in secondary structures is defined in paper [77] as

$$
\frac{\mathrm{d} S_{\mathrm{m}}}{\mathrm{d} t}=J_{\mathrm{m}} X_{\mathrm{m}},
$$

where $J_{\mathrm{m}}$ is the flux of matter, $X_{\mathrm{m}}$ is the thermodynamic force initiating the matter flux, and $X_{\mathrm{m}}=(\operatorname{grad} C) / T(C$ is the concentration of substance). According to the Fick law, the expression for matter transfer assumes the form $J_{\mathrm{m}}=$ $m_{\mathrm{e}}-D \operatorname{grad} C$ ( $D$ is the diffusion coefficient).

A change in the production of heat flux entropy is expressed as

$$
\frac{\mathrm{d} S_{\mathrm{q}}}{\mathrm{d} t}=J_{\mathrm{q}} X_{\mathrm{q}},
$$

where $J_{\mathrm{q}}$ is the heat flux, and $X_{\mathrm{q}}=(\operatorname{grad} T) / T^{2}$ is the thermodynamic force initiating heat flux ( $T$ is temperature) in accordance with the Biot-Fourier law of heat conduction: $J_{\mathrm{q}}=-\lambda \operatorname{grad} T$ ( $\lambda$ is heat conductivity). It is assumed that only part $(X)$ of mechanical friction energy is dissipated into the heat flux.

A change in the entropy of the flow of physico-chemical transformations in secondary structures with time is defined as [77]

$$
\frac{\mathrm{d} S_{\mathrm{f}}}{\mathrm{d} t}=J_{\mathrm{ch}} X_{\mathrm{ch}}
$$

where $J_{\mathrm{ch}}$ is the rate of chemical reactions, and $X_{\mathrm{ch}}$ is the thermodynamic force initiating chemical reactions: $X_{\text {ch }}=A / T$ ( $A$ is chemical affinity).

SS entropy production in the system of interest (disregarding the relationship among the fluxes) is given by

$$
\frac{\mathrm{d} S}{\mathrm{~d} t}=\frac{\left(f_{\mathrm{m}} p_{\mathrm{r}} v X\right)^{2}}{\lambda T^{2}}+f_{\mathrm{m}} p_{\mathrm{r}} v Y \frac{m_{\mathrm{e}}}{D T},
$$

where $f_{\mathrm{m}}$ is the coefficient of friction, $p_{\mathrm{r}}$ is the specific normal load, $v$ is the sliding velocity, $X$ is that part of the mechanical friction energy dissipated into heat, $Y$ is that part of the total entropy production under friction spent to form a matter flux, and $m_{\mathrm{e}}$ is the flux of matter.

In accordance with the Prigogine universal criterion [89], part of the change in entropy production associated with the change in thermodynamic forces during the evolution of a thermodynamic system should be negative. It cannot be stated unambiguously what sign that part of the change in entropy production related to the change in thermodynamic fluxes will have. It is known, however, that if the entropy production of the system decreases with changing thermodynamic fluxes and forces, it falls to a minimum in a steady state and remains unaltered thereafter. It is assumed based on this theorem that entropy production in a tribological system in the steady state can remain constant within a certain range of friction parameter variations. The tribological system acquires such stability only after the loss of thermodynamic stability and formation of dissipative structures.

Unspontaneous processes are sustainable if dissipative structures are formed during self-organization. Self-organization (adaptation) may begin after the system has passed through instability $[87,88]$.

The notion of entropy production rate is not crucial for the evolution of dynamic systems of nanocomposite multicomponent protective coatings described by kinetic schemes with the determinate behavior in time, in contrast to nearequilibrium systems. Indeed, the trajectories of evolution of such systems are strictly determinate and final states in the course of such evolution are usually impossible to predict by comparing statistical ordering of the initial and final states. Both the possibilities and means of achieving one final state or another depend on the starting conditions and a concrete set of differential equations describing the kinetics of transformations.

Nanocomposite multicomponent protective coatings perform two functions. First, they facilitate further accumulation and dissipation of energy, thus reducing surface damages and their propagation in the form of cracks and thereby decreasing the wear rate. Second, they maintain stable regeneration of tribological films inserted into the surface of the main coating. One of the most efficient methods for implementing these two functions is the application of coatings with a multilayer nanostructure, capable of effective 
accumulation and dissipation of thermomechanical energy delivered to the friction surface. As was mentioned in a preceding paragraph, this purpose can be achieved in multilayer coatings composed of alternating nanolayers with different and modulated chemical compositions.

Poor performance indicators of binary nitride coatings (TiN, ZrN, HfN, etc.) prompted the idea of doping binary compositions with additional elements ( $\mathrm{Al}, \mathrm{Cr}, \mathrm{Si}, \mathrm{B}$, etc.) to improve their characteristics. As a result, a variety of hard nanocomposite coatings with improved properties have been created [9-31]. Most recent achievements in instrumental materials engineering have the potential to reducing friction in the cutting zone and energy consumption during processing operations, along with a simultaneous extension of the lifespan of the coated tools. The development of adaptive instrumental coatings for manufacturing high-temperature lubricious (often also referred to as Magnéli phases) vanadium, molybdenum, and other metal oxides [28, 29] is a priority field of tool coating research.

\section{Extensive studies of tribotechnical coatings}

The ever-increasing demands of the aerospace, aviation, atomic, machine-building and other industries for highquality, functionally flexible, and environmentally friendly materials necessitate special attention to the choice of constituent elements and means of control (modification) of the structural-phase state. Successful application of such processes as thermal-chemical treatment, nitriding, and carbonitriding. makes possible manufacturing products with high performance and longer lifetimes. Of primary importance is the creation and improvement of tribological characteristics of new materials to be used under extreme conditions, such as ionizing radiation, high temperatures (up to $1000^{\circ} \mathrm{C}$ ), wear under cyclic contact, and deep vacuum.

Materials with low friction coefficients and wear rate in a wide temperature range can be divided into five classes: (1) diamond-like carbon films (so-called DLC coatings), (2) metal nitrides ( $\mathrm{TiN}, \mathrm{CrN})$, (3) transition metal- and dichalcogenide $\left(\mathrm{MoS}_{2}, \mathrm{WS}_{2}\right)$-based materials, (4) polymers, and (5) soft metals (silver, copper, gold). Disadvantages of the above ceramic and metal-ceramic composite materials include poor lubricating properties at room temperature responsible for undesirable heating at contact sites and restricting the scope of their applications. To recall, there are still no coatings with stable friction characteristics in a broad temperature range (up to $1000^{\circ} \mathrm{C}$ ).

One of the most successful approaches to the solution to this problem is the development of nanocomposite coatings differing in internal structural hierarchy based on transition metal nitrides, oxides, and other derivatives. As a review of the literature showed, coatings formed of composite materials consisting of several constituents possess a combination of desired antifriction properties. For example, oxides can be utilized to increase heat resistance, and transition metal nitrides are instrumental in the improvement of mechanical properties, whereas doping with silver, carbon, or molybdenum lowers friction coefficients in a range of moderate and low temperatures, thereby promoting the adaptive behavior of protective coatings.

\subsection{Coatings with the adaptive friction mechanism}

Numerous current publications deal with tribological and wear characteristics of coatings with reference to processes in the contact region. The most promising are materials capable of changing their properties depending on operational conditions (so-called adaptive coatings or 'chameleons'). An improvement in their antifriction characteristics can be achieved by combining hard and wear-resistant materials with antifriction components. One of the first coatings of this type is the WC/DLC/WS 2 composite [49] based on a hydrogen-free diamond-like carbon (DLC) film showing high operational properties depending on the manufacturing conditions (hardness of 50-60 GPa, modulus of elasticity of 400-600 GPa, friction coefficient of 0.05-0.1) [93-95]. A disadvantage of such materials is that their antifriction characteristics deteriorate at elevated temperatures (350$400{ }^{\circ} \mathrm{C}$ ) largely due to transition from $\mathrm{sp}^{3}$ interatomic bonds to $\mathrm{sp}^{2}$ ones.

The author of Ref. [96] proposed building up WC/DLC/ $\mathrm{WS}_{2}$ coatings with an antifriction component based on a $\mathrm{WS}_{2}$ material widely used in the aerospace industry and having a low friction coefficient $(0.02-0.04)$ in a vacuum, inert gases, and dry air up to $1500^{\circ} \mathrm{C}$. The lubricating effect of the transition metal dichalcogenides $\left(\mathrm{WS}_{2}, \mathrm{MoS}_{2}, \mathrm{NbSe}_{2}\right.$, etc.) is primarily due to the layer-by-layer arrangement of metal and chalcogenide atoms, as well as to the weak van der Waals bonding between the planes [97, 98]. The efficiency of exploiting such materials sharply decreases in moist air, where their friction coefficient rises abruptly (up to 0.15) owing to the formation of metal oxides with abrasive properties on the surface. The additional doping of a $\mathrm{WS}_{2}$ based coating with carbon and noble metals is known to produce a beneficial effect on its tribological properties, attributable to the expansion of interplanar spacing and weakening of van der Waals bonds that facilitate sliding and inhibits oxidation by interfering with oxygen diffusion from the surface.

Investigations into the tribological characteristics of $\mathrm{WC} / \mathrm{DLC} / \mathrm{WS}_{2}$ coatings have revealed variations of the friction coefficient from 0.1 to 0.007 depending on testing conditions ( 0.1 in a moist atmosphere, 0.03 in a vacuum, 0.007 in dry nitrogen). At an elevated temperature $\left(300^{\circ} \mathrm{C}\right)$, the coating adapted itself much worse to the environmental conditions probably due to the high chemical activity of tungsten chalcogenide $\left(\mathrm{WS}_{2}\right)$ in moist air [96].

Considerable interest has recently been shown in materials in the form of multiphase structures, such as solid lubricants (Au or $\mathrm{Ag}$ ) dispersed in a hard matrix (transition metal nitrides), owing to their markedly reduced friction coefficient and wear rate in a wide temperature range. By way of example, $\mathrm{Al} / \mathrm{Au}$ [99], $\mathrm{Mo}_{2} \mathrm{~N} / \mathrm{Ag}[100,101]$, TiN/Ag [102], NbN/Ag [60, 90], TaN/Ag [103], CrN/Ag [104, 105], $\mathrm{ZrN} / \mathrm{Ag}$ [106], VN/Ag [107], and CrAlN/Ag [108] composites were synthesized and investigated. Binary compounds exemplified by nitride-transition metal complexes are known to make up poor antifriction coatings due to a relatively low oxidation temperature and high friction coefficients equaling 0.9 for TaN, 0.35 for $\mathrm{Mo}_{2} \mathrm{~N}, 0.17$ for TiN, 0.16 for $\mathrm{CrN}, 0.19$ for $\mathrm{ZrN}, 0.8$ for $\mathrm{VN}, 0.89$ for $\mathrm{NbN}$, and 0.37 for CrAIN. An analysis of the literature showed that doping with soft metals ensures low shear stress in the contact region under friction loading, which improves the friction coefficient [109].

The authors of Ref. [110] studied $\mathrm{CrN} / \mathrm{Ag}, \mathrm{ZrN} / \mathrm{Ag}$, $\mathrm{TiN} / \mathrm{Ag}$, and $\mathrm{TiN} / \mathrm{Cu}$ coatings obtained by magnetron sputtering. Electron (SEM) micrographs of $\mathrm{CrN} / \mathrm{Ag}$ cross sections presented in Figs $6 \mathrm{a}, \mathrm{b}$ show that silver or copper doping leads to compaction of the structure. Silver particles 

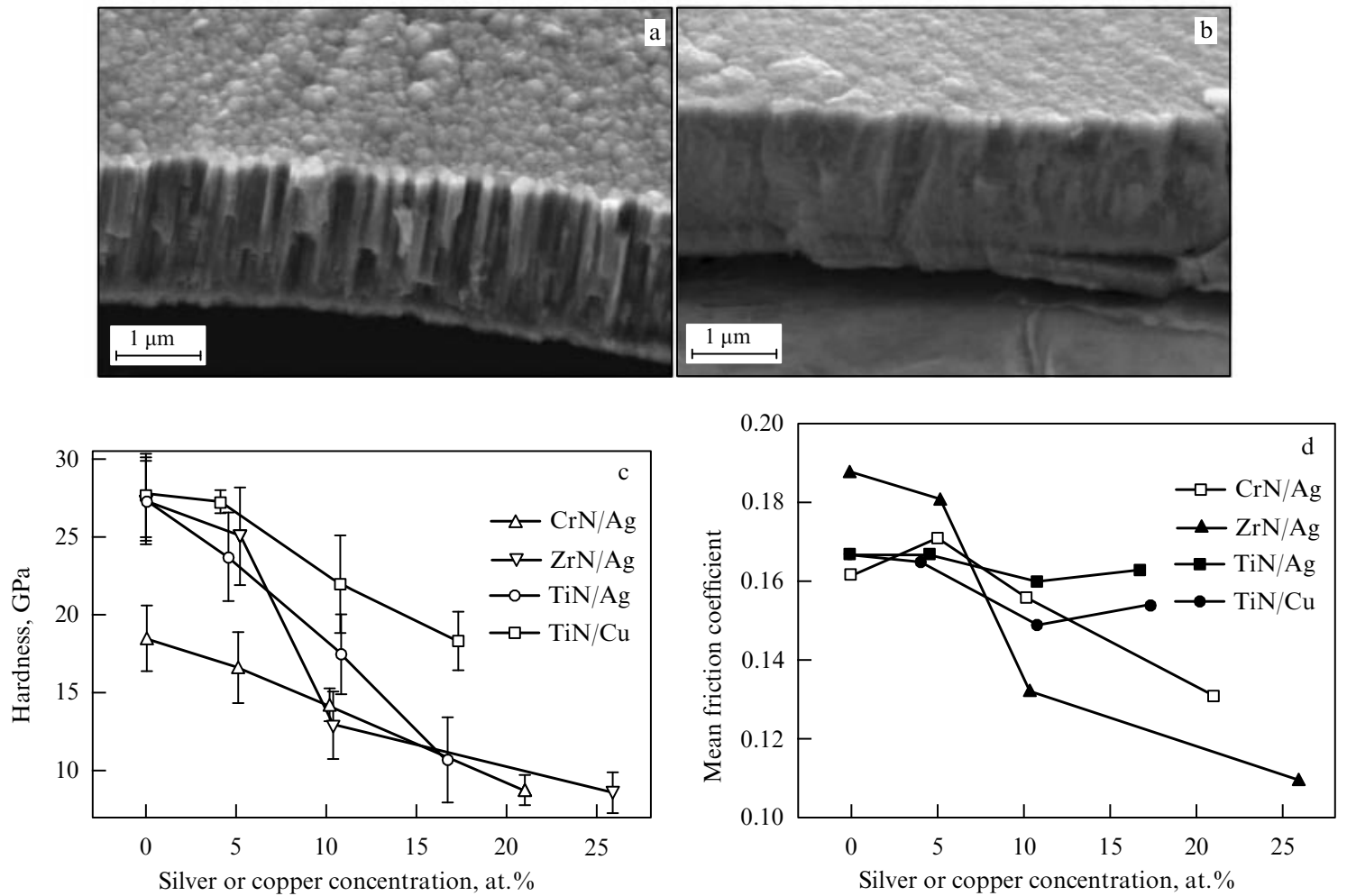

Figure 6. Microphotographs of fracture zones: (a) $\mathrm{CrN}$, (b) $\mathrm{CrN} / 10.2$ at.\% $\mathrm{Ag}$. Hardness (c) and mean friction coefficient (d) of CrN/Ag, $\mathrm{ZrN} / \mathrm{Ag}$, $\mathrm{TiN} / \mathrm{Ag}$, and TiN/Cu nanocomposite coatings (from Ref. [110]).

from 25 to $50 \mathrm{~nm}$ in size were also found in transition metal nitride matrices. Results of studies on mechanical and tribological properties of coatings are presented in Figs 6c, d. Silver and copper doping was shown to markedly reduce the hardness of the coatings from 28-18 to 19-9 GPa, depending on the metal making up the substrate; simultaneously, the friction coefficient decreases, especially for $\mathrm{ZrN} / \mathrm{Ag}$ (to 0.11 at a silver concentration of 29.3 at. \%).

Studies of antifrictional properties of $\mathrm{NbN} / \mathrm{Ag}$ coating a various temperatures are reported in Ref. [60]. An X-ray phase analysis has demonstrated that this coating has a nanocomposite structure formed by $\mathrm{Ag}$ grains in the $\mathrm{NbN}$ matrix. A rise in temperature decreases the friction coefficient for a pure nitride from 0.89 at $25^{\circ} \mathrm{C}$ to 0.7 and 0.53 at 350 and $750{ }^{\circ} \mathrm{C}$, respectively. The friction coefficient for $\mathrm{NbN} / \mathrm{Ag}$ changed from 0.35 to 0.3 and 0.27 at 25,350 , and $750^{\circ} \mathrm{C}$, respectively. Structural-phase studies in the low-temperature interval after wear testing (Fig. 7) revealed the migration of silver nanoparticles toward the surface accompanied by a reduction in the friction coefficient. A rise in temperature activated oxidation giving rise to the formation of metal oxide $\left(\mathrm{AgNbO}_{3}\right.$ or silver niobate). At $750{ }^{\circ} \mathrm{C}$, the peak in position of $240 \mathrm{~cm}^{-1}$ corresponded to $\mathrm{Nb}_{2} \mathrm{O}_{5}$ oxide; its intensity decreased as the number of wear test cycles increased. Thus, the adaptive behavior of the $\mathrm{NbN} / \mathrm{Ag}$ coating is due to $\mathrm{Ag}$ diffusion toward the coating surface with subsequent oxidation and formation of lubricious silver niobate.

Similar results were obtained in $\mathrm{TaN} / \mathrm{Ag}$ and $\mathrm{VN} / \mathrm{Ag}$ studies [103, 107]. According to X-ray diffraction analysis (XRD) data [103], TaN/Ag coatings containing approximately 20 at. $\% \mathrm{Ag}$ had a nanocomposite structure consisting of cubic $\mathrm{Ag}$ grains and the TaN matrix. Changes in temperature from 25 to $750{ }^{\circ} \mathrm{C}$ not only reduced the friction coefficient from 0.39 to 0.23 for $\mathrm{TaN} / \mathrm{Ag}$ but also produced peaks in the Raman spectrum corresponding to the presence of $\mathrm{AgTaO}_{3}$ and $\mathrm{Ta}_{2} \mathrm{O}_{5}$ oxides [103]. A change in temperature improved the tribological properties of $\mathrm{VN} / \mathrm{Ag}$ (the friction coefficient at 42 at. $\% \mathrm{Ag}$ was $0.37,0.30,0.12$, and 0.20 at 25 , 350,700 , and $1000^{\circ} \mathrm{C}$, respectively. In this case, adapting $\mathrm{VN} / \mathrm{Ag}$ and $\mathrm{TaN} / \mathrm{Ag}$ to the friction process at high temperatures was achieved owing to the formation of lubricious silver vanadate and tantalite, respectively.

Of special interest is study [108] reporting the dependence of friction coefficients at room temperature on a silver concentration in CrAlN/Ag coatings. Transmission electron micrographs (TEMs) of their cross sections (Fig. 8a) show 4 $8 \mathrm{~nm} \mathrm{Ag} \mathrm{nanograins} \mathrm{(dark} \mathrm{areas)} \mathrm{surrounded} \mathrm{by} \mathrm{a} \mathrm{CrAlN}$ matrix (light areas).

It was revealed that the friction coefficient decreased to 0.23 at a doping concentration of silver equal to 9 at. \%. Its further rise resulted in a marked deterioration of antifriction characteristics; Basnyat et al. [108] ascribed this change to structural-phase transformations of the surface. For example, inclusion of silver in the coating caused reorientation of the mixture from $(111)+(200)$ to (111) (see Ref. [108]). The optimal silver concentration amounted to 28 at. $\%$ for $\mathrm{VN} / \mathrm{Ag}, 10.8$ at. $\%$ for $\mathrm{TiN} / \mathrm{Ag}, 25.9$ at. $\%$ for $\mathrm{ZrN} / \mathrm{Ag}$, 21 at. $\%$ for $\mathrm{CrN} / \mathrm{Ag}$, and 24 at. $\%$ for TaN/Ag. A deviation of $\mathrm{Ag}$ concentration in $\mathrm{CrAlN} / \mathrm{Ag}$ from the optimal value was accompanied by a change in its nanostructure and resulting deterioration of hardness and the elastic modulus. This and the absence of conditions for the formation of lubricating Ag-phases worsened the antifriction characteristics of the coating.

The authors of Ref. [111] designed a tribological product in the form of an adaptive $\mathrm{YSZ}-\mathrm{Ag}-\mathrm{Mo}$ coating in which $\mathrm{Ag}$ 

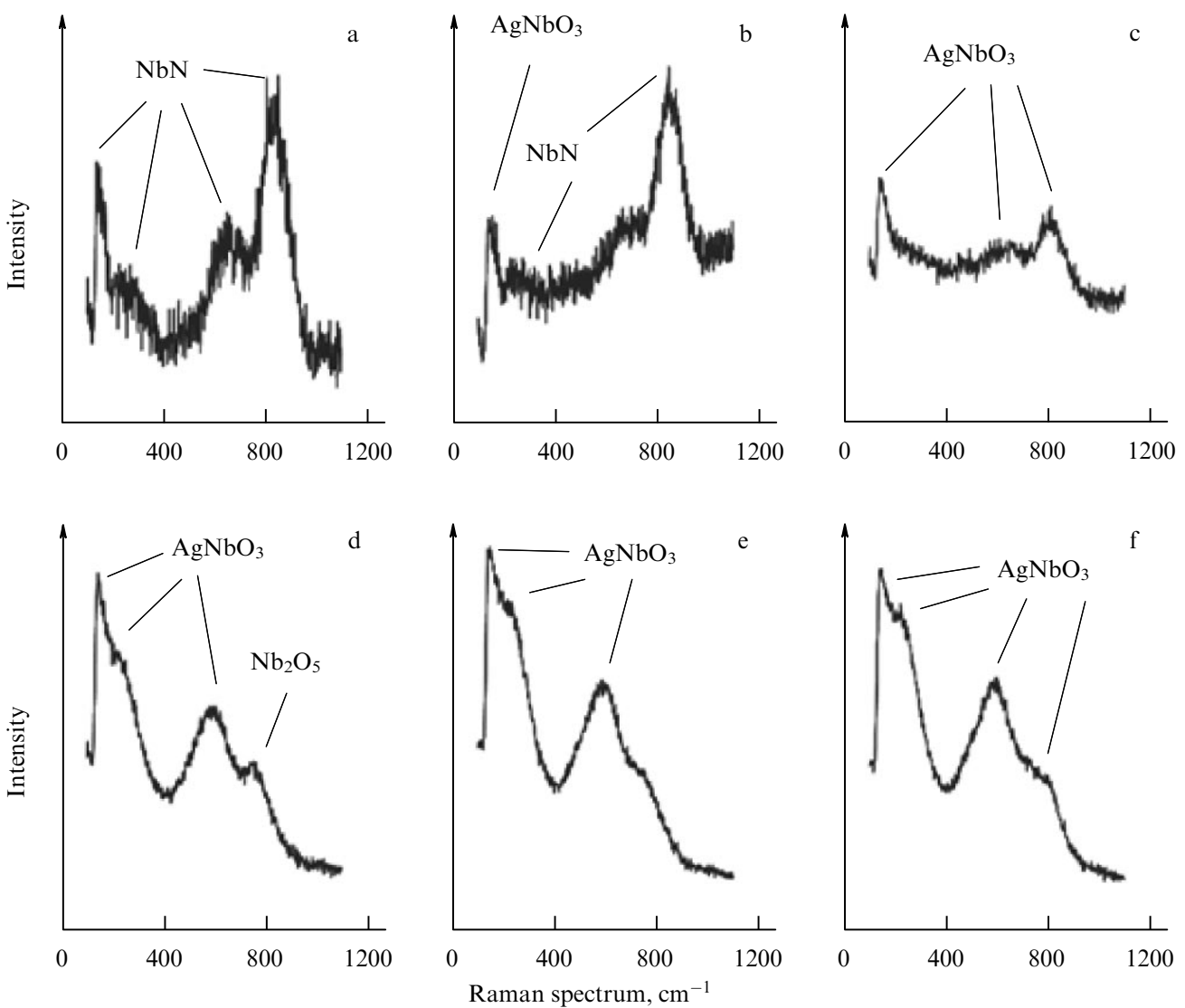

Figure 7. Raman scattering spectra of the $\mathrm{NbN} / \mathrm{Ag}$ coating at: (a) $25^{\circ} \mathrm{C}$, (b) $500^{\circ} \mathrm{C}$, (c) $600^{\circ} \mathrm{C}$, and (d) $750^{\circ} \mathrm{C}$, and during a wear test after 500 (e) and 10,000 (f) cycles (from Ref. [60]).

crystal grains $<20 \mathrm{~nm}$ in size were inserted into the nanocrystalline /amorphous zirconium dioxide matrix partly stabilized by yttrium oxide (yttria-stabilized zirconia - YSZ) (Fig. 9a). It was shown in Ref. [112] that a rise in Ag content up to 24 at. \% allowed the friction coefficient to be reduced from $\sim 0.8$ to even $\sim 0.24$; however, the lifespan of the resultant coating did not exceed 4500 cycles (Fig. 9d).

According to Ref. [112], one of the causes behind the relatively short lifespan of the coating can be the diffusion of metal atoms toward the surface. A rise in temperature to
$>300{ }^{\circ} \mathrm{C}$ activated the diffusion of metals from heavily strained sites in the YSZ matrix to the surface. As a result, atoms of the noble metal became distributed over the entire surface and thereby depleted it of lubricious phases. The addition of 24 at.\% Ag improved the friction properties of YSZ both at low and moderate temperatures, while the formation of $\mathrm{MoO}_{3}$ at $700{ }^{\circ} \mathrm{C}$ decreased the friction coefficient. Such a hierarchical structure of the nanocomposite promoted its adaptation within a rather wide range of temperatures from their room values to $700^{\circ} \mathrm{C}$, while the
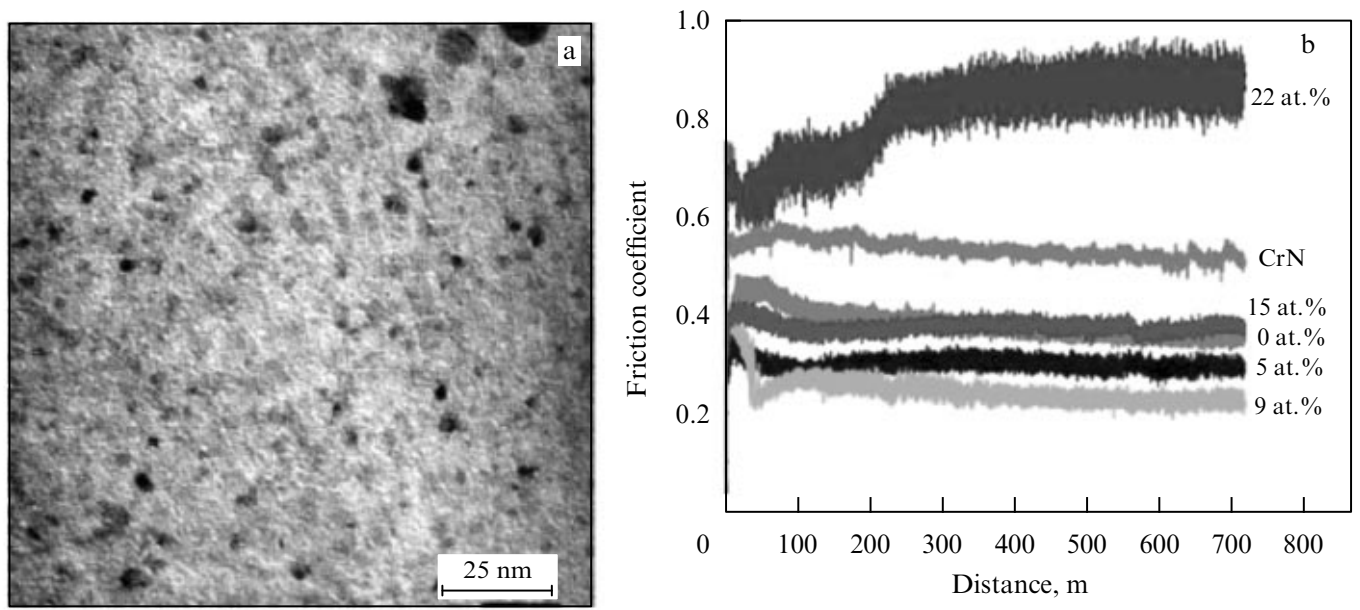

Figure 8. (a) TEM image of CrAlN/Ag cross section (Ag concentration $\sim 9$ at. \%). (b) CrAlN/Ag friction coefficient at various silver concentrations (from Ref. [108]). 

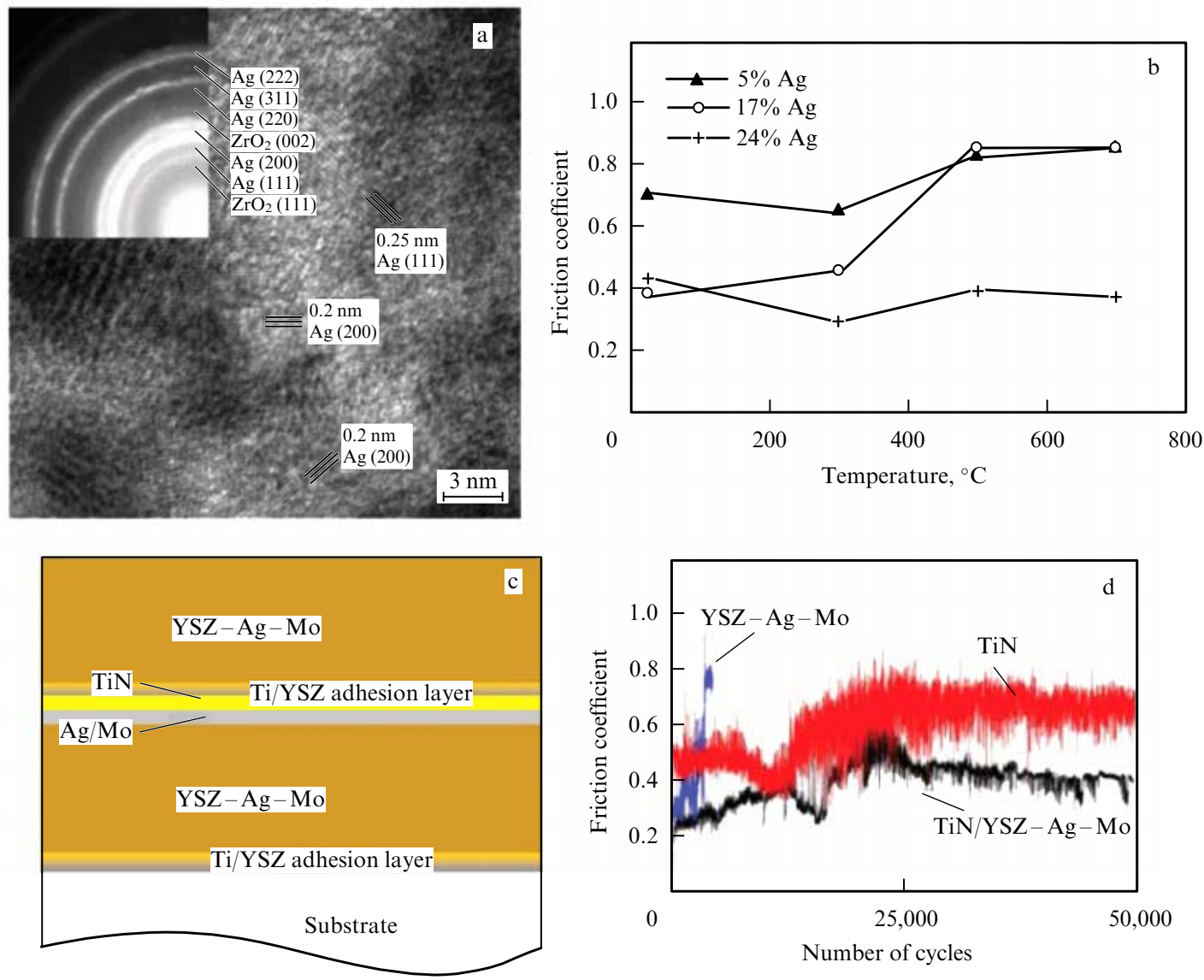

Figure 9. (a) TEM image of a nanocomposite YSZ-Ag-Mo (24 at. \% Ag, 10 at.\% Mo) coating cross section. Inset: electron diffraction pattern in the respective region; (b) variation of friction coefficient for $\mathrm{YSZ}-\mathrm{Ag}-\mathrm{Mo}$ nanocomposite with different $\mathrm{Ag}$ content and 10 at. \% Mo at temperatures from room value to $700^{\circ} \mathrm{C}$; (c) schematic of multilayer YSZ-Ag-Mo nanocomposite divided by TiN diffusion barrier, and (d) friction coefficient in the air at $500^{\circ} \mathrm{C}$ for TiN/YSZ-Ag-Mo, YSZ-Ag-Mo, and TiN coatings (from Refs [58, 112]).

lifespan of the coating was determined by the amounts of elements responsible for the emergence of lubricious phases at different stages of operation.

It is well known that transition metal nitrides serve as efficient diffusion barriers for noble metals [113, 114]. Thus, the authors of Ref. [58] prolonged the lifespan of a YSZ-AgMo composite using an amorphous-crystalline TiN/YSZAg-Mo coating with a TiN diffusion barrier introduced into the YSZ-Ag-Mo bulk to control silver diffusion (Fig. 9b). Figure 9d illustrates the frictional behavior of the coating at $500{ }^{\circ} \mathrm{C}$. Evidently, the YSZ-Ag-Mo coating became completely destroyed after 4500 cycles, as confirmed by the abrupt rise in the friction coefficient from 0.4 to 0.8 . The friction coefficient of a multilayer TiN/YSZ-Ag-Mo coating remained equal to 0.4 throughout 25,000 cycles. The authors believe a reduction in the friction coefficient can be attributed to the diffusion of $\mathrm{Ag}$ atoms from the lower $\mathrm{YSZ}-\mathrm{Ag}-\mathrm{Mo}$ layer to the protective TiN layer, whereas Ag grains in the upper YSZ-Ag-Mo layer were uniformly distributed over the entire coating.

The lifetime of a nanocomposite $\mathrm{YSZ}-\mathrm{Ag}-\mathrm{Mo}$ coating was even more prolonged after applying the TiN surface porous mask [112]. This approach made it possible to confine the transfer of lubricating silver into a coating surface and thereby to reduce the rate of its depletion at high temperatures. As a result of coating heating up $500^{\circ} \mathrm{C}$, the formation of dome-like silver islets of $10-50 \mu \mathrm{m}$ in size takes place on the
YSZ-Ag-Mo nanocomposite surface in TiN pores [112], which allowed increasing the operation time of the coating up to 50,000 cycles, with the coefficient of friction maintained at a level of $\sim 0.4$.

One of the concepts on which the development of tribological products is based gives priority to multilayer (multiphase) coatings containing hard and antifriction layers exemplified by $\mathrm{Mo}_{2} \mathrm{~N} / \mathrm{MoS}_{2} / \mathrm{Ag}$ [115]. According to Ref. [115], such a design makes it possible to realize various adaptive mechanisms, depending on the working temperature. For example, $\mathrm{MoS}_{2}$ functions as a self-lubricant at relatively low temperatures $\left(300^{\circ} \mathrm{C}\right)$ by virtue primarily of its layered structure. In a temperature range from 300 to $500{ }^{\circ} \mathrm{C}$, friction decreases due to silver atom diffusion toward the surface of a product. At a temperature of $500{ }^{\circ} \mathrm{C}$, lubricating compounds form in $\mathrm{MoS}_{2} / \mathrm{Ag}$ interactions followed by $\operatorname{AgMoS}_{x}$ synthesis. A further increase in temperature promotes oxidation to $\mathrm{AgMo}_{x} \mathrm{O}_{y}$ type composites as a result of oxygen substitution for silver atoms.

An evaluation of the structural-phase state of the $\mathrm{Mo}_{2} \mathrm{~N} / \mathrm{MoS}_{2} / \mathrm{Ag}$ coating revealed three phases, viz. Ag, $\mathrm{MoS}_{2}$, and $\beta-\mathrm{Mo}_{2} \mathrm{~N}$. Results of elemental analyses and investigations of tribological characteristics of this coating are presented in the table. The friction coefficient was measured using a silicon nitride counterbody at room temperature, $350{ }^{\circ} \mathrm{C}$, and $600^{\circ} \mathrm{C}$. It was shown that a rise in temperature tended to decrease the friction coefficient from 
Table. Results of elemental analyses and evaluations of friction characteristics of the $\mathrm{Mo}_{2} \mathrm{~N} / \mathrm{MoS}_{2} / \mathrm{Ag}$ system [103].

\begin{tabular}{|c|c|c|c|c|c|}
\hline & S- $48-20$ & S-60-60 & S-30-20 & S-42-0 & S- $0-0$ \\
\hline \multicolumn{6}{|c|}{ Coating } \\
\hline Mo, at. $\%$ & 40 & 40 & 45 & 47 & 63 \\
\hline $\mathrm{N}$, at. $\%$ & 35 & 27 & 34 & 28 & 37 \\
\hline $\mathrm{S}$, at. $\%$ & 4 & 12 & 5 & 0 & 0 \\
\hline Ag, at. $\%$ & 21 & 21 & 16 & 25 & 0 \\
\hline \multicolumn{6}{|c|}{ Friction coefficient } \\
\hline Room temperature & $0.40 \pm 0.02$ & $0.60 \pm 0.03$ & $0.52 \pm 0.03$ & $0.60 \pm 0.04$ & $0.70 \pm 0.04$ \\
\hline $350^{\circ} \mathrm{C}$ & $0.30 \pm 0.02$ & $0.38 \pm 0.02$ & $0.40 \pm 0.02$ & $0.42 \pm 0.02$ & $0.80 \pm 0.05$ \\
\hline $600^{\circ} \mathrm{C}$ & $0.10 \pm 0.02$ & $0.15 \pm 0.02$ & $0.12 \pm 0.02$ & $0.40 \pm 0.02$ & $0.72 \pm 0.04$ \\
\hline \multicolumn{6}{|c|}{ Wear rate, $\mathrm{mm}^{3} \mathrm{~N}^{-1} \mathrm{~m}^{-1}$} \\
\hline Room temperature & $2 \times 10^{-5}$ & $8 \times 10^{-5}$ & $7 \times 10^{-5}$ & $7 \times 10^{-4}$ & $6 \times 10^{-5}$ \\
\hline $350^{\circ} \mathrm{C}$ & $6 \times 10^{-6}$ & $2 \times 10^{-5}$ & $7 \times 10^{-5}$ & $5 \times 10^{-5}$ & $7 \times 10^{-5}$ \\
\hline $600^{\circ} \mathrm{C}$ & $8 \times 10^{-7}$ & $1 \times 10^{-5}$ & $1 \times 10^{-5}$ & $9 \times 10^{-5}$ & $5 \times 10^{-4}$ \\
\hline
\end{tabular}

0.4-0.7 at room temperature to 0.3 at $350^{\circ} \mathrm{C}$. The coating adapted itself to friction conditions at $350{ }^{\circ} \mathrm{C}$ due to simultaneous formation of $\mathrm{Ag}$ and $\mathrm{MoO}_{3}$ agglomerations uniformly distributed over the coating surface. Elevating the temperature to $600{ }^{\circ} \mathrm{C}$ gave rise to silver molybdate phases $\mathrm{Ag}_{2} \mathrm{Mo}_{4} \mathrm{O}_{13}, \mathrm{Ag}_{2} \mathrm{Mo}_{2} \mathrm{O}_{7}$, and $\mathrm{Ag}_{2} \mathrm{MoO}_{4}$, which improved the friction characteristics of the coating (a friction coefficient of 0.1 during 300,000 test cycles). As is known, the low friction coefficient of the above phases is due to the sliding of planes relative to each other, facilitated by weak interatomic $\mathrm{Ag}-\mathrm{O}$ bonds [115].

The $\mathrm{YSZ} / \mathrm{Au} / \mathrm{MoS}_{2} / \mathrm{DLC}$ system provides another example of multiphase antifriction coatings [56]. Its X-ray structural analysis in Ref. [56] suggested the formation of a nanocomposite structure containing YSZ and Au nanocrystallites $2-3$ and $4-5 \mathrm{~nm}$ in size, respectively. Studies of the friction characteristics of the $\mathrm{YSZ} / \mathrm{Au} / \mathrm{MoS}_{2} / \mathrm{DLC}$ coating in various media revealed variations of the friction coefficient in dry nitrogen between 0.03 and 0.04 , i.e., close to the values for $\mathrm{MoS}_{2}$ under similar testing conditions [116]. In addition, these values are comparable to the friction coefficient for a partly graphitized diamond-like film in the air at a relative humidity of $40 \%(0-0.15)$ [117] and for coatings with a noble metal film on the surface in the air at $500{ }^{\circ} \mathrm{C}$ under laboratory conditions (0.25-0.30) [118].

A structural studies of a film of transferred counterbody material gave evidence of a transfer of hexagonal $\mathrm{MoS}_{2}$ with the formation of $\mathrm{MoO}_{3}$ oxide in dry nitrogen and of graphitelike carbon in the air at a relative humidity of $40 \%$. To recall, the YSZ/Au/ $\mathrm{MoS}_{2} / \mathrm{DLC}$ coating is a softer coating than DLC, as follows from the stability of friction characteristics throughout 70,000-80,000 versus 200,000 test cycles. It was revealed that gold agglomerates on the coating surface in the air at $500{ }^{\circ} \mathrm{C}[56,58,111]$. Such coatings failure even after 5000-10,000 testing cycles. Therefore, according to paper [56], there are a variety of adaptive mechanisms responsible for the lubricating effect.

The magnetron sputtering technique, in combination with laser ablation, was employed in Ref. [119] to prepare multiphase $\mathrm{Al}_{2} \mathrm{O}_{3} / \mathrm{DLC} / \mathrm{Au} / \mathrm{MoS}_{2}$ coatings having a nanocomposite structure with $<10 \mathrm{~nm} \mathrm{Ag}$ nanocrystallites included in the amorphous matrix consisting of $\mathrm{Al}_{2} \mathrm{O}_{3}, \mathrm{DLC}$, and $\mathrm{MoS}_{2}$. Tribological studies of $\mathrm{Al}_{2} \mathrm{O}_{3} / \mathrm{DLC} / \mathrm{Au} / \mathrm{MoS}_{2}$ coatings with various chemical compositions allowed the authors of [119] to determine their optimal composition to be $\left(\mathrm{Al}_{2} \mathrm{O}_{3}\right)_{0.47} / \mathrm{C}_{0.12} / \mathrm{Au}_{0.15} /\left(\mathrm{MoS}_{2}\right)_{0.24}$. They showed that coatings with a high $\mathrm{Al}_{2} \mathrm{O}_{3}$ or $\mathrm{C}$ content (62 at. $\%$ and $>20$ at. $\%$, respectively) had enhanced friction coefficients and a short lifespan. A rise in the soft phase concentration ( $\mathrm{Au}$ over 20 at. \%) produced a detrimental effect on the lifespan. The studies performed have made it possible to establish that the friction coefficient of $\left(\mathrm{Al}_{2} \mathrm{O}_{3}\right)_{0.47} / \mathrm{C}_{0.12} / \mathrm{Au}_{0.15} /\left(\mathrm{MoS}_{2}\right)_{0.24}$ was $0.13-0.14$ in moist air, $0.02-0.03$ in dry nitrogen, and 0.1 in the air at $500^{\circ} \mathrm{C}$.

Ternary nitrides and carbides based on $M_{n+1} A X_{n}$ phases $(M$ - transition metal, $A-$ group A element, and $X-\mathrm{C}$ or $\mathrm{N})$ are the most interesting and promising for potential applications among adaptive coatings exposed to dry friction [120-129]. These materials, having a thermodynamically stable atomically layered hexagonal structure (a spatial $D_{6 h}^{4}-P 6_{3} / m m c$ group) with extremely strong mixed metallic covalent $M-X$ bonds and relatively weak $M-A$ bonds, can exhibit a self-lubricating behavior at room and elevated temperatures. It was shown in Ref. [130] that transition from a multilayer $\mathrm{Ti}-\mathrm{Si}-\mathrm{C}$ structure to the $M A X$-phases of $\mathrm{Ti}_{3} \mathrm{SiC}_{2}$ after high-temperature annealing is accompanied by a change in the wear mechanism without alteration of the friction coefficient (Fig. 10).

At the initial stage of tribological tests, the wear was governed by the tribo-oxidation mechanism but thereafter switched over to the self-lubrication regime with the formation of a tribological film. The formation of $\mathrm{Ti}_{2} \mathrm{AlN}$ after thermal annealing of multilayer $\mathrm{Ti}-\mathrm{Al}-\mathrm{N}$ coatings markedly reduced the friction coefficient under a small loading, which is largely determined by the surface elemental composition. Nevertheless, the friction coefficient of $\mathrm{Cr}_{2} \mathrm{AlC}$ coatings turned out to be higher than in a multilayer $\mathrm{Cr}-\mathrm{Al}-\mathrm{C}$ coating. Wear resistance tests revealed abrasive wear with the formation of wear fragments in the coating even though $M A X$-phases of $\mathrm{Cr}_{2} \mathrm{AlC}$ did not undergo complete destruction after test ending. As a result, the coating consisting of $M A X$-phases possessed enhanced resistance to mechanical 

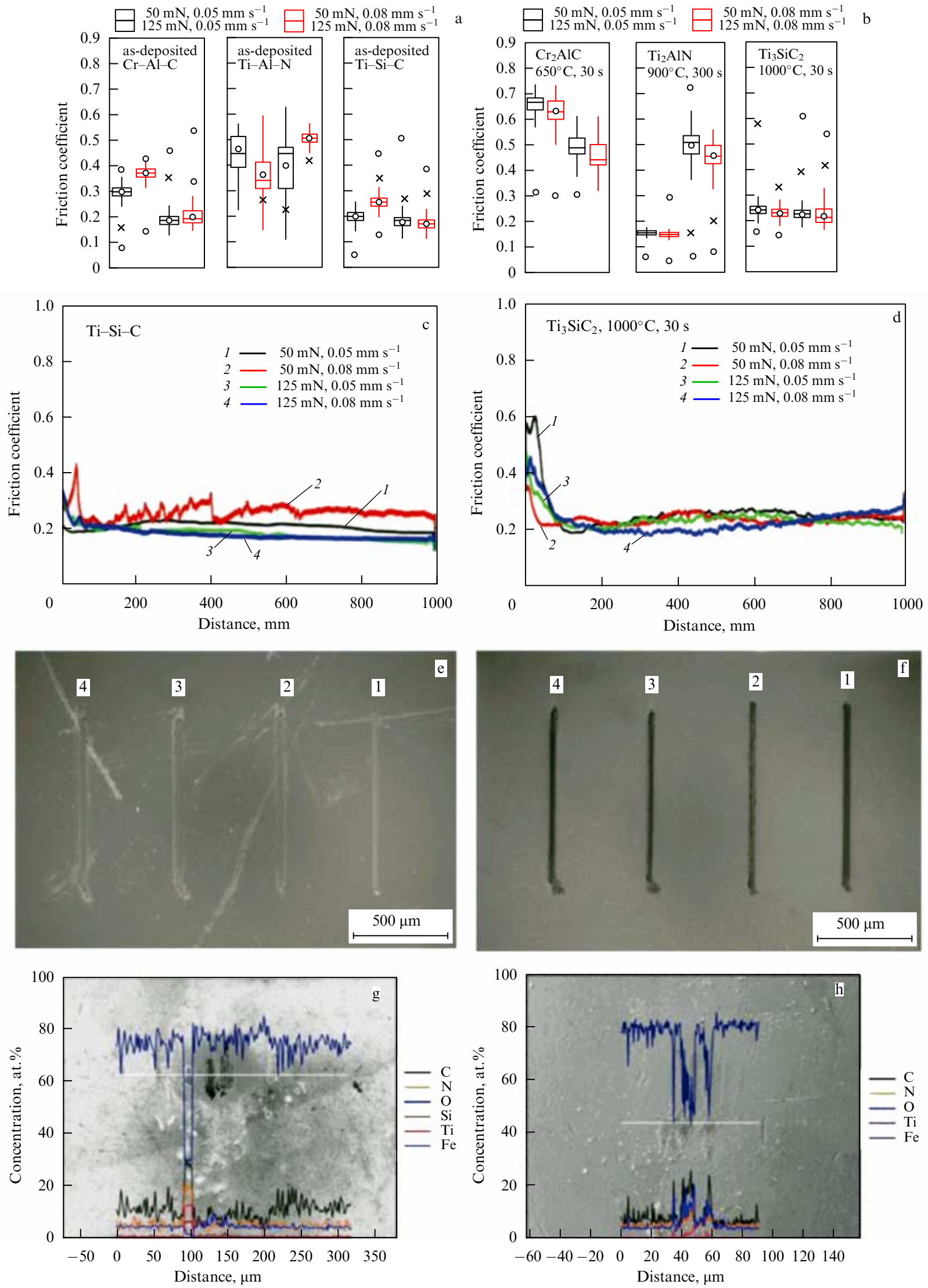

Figure 10. (Color online.) Statistical diagrams of friction coefficient: (a) multilayer $\mathrm{Cr}-\mathrm{Al}-\mathrm{C}, \mathrm{Ti}-\mathrm{Al}-\mathrm{N}$, Ti-Si-C coatings, and (b) coatings based on the $M A X$-phases of $\mathrm{Cr}_{2} \mathrm{AlC}, \mathrm{Ti}_{2} \mathrm{AlN}$, and $\mathrm{Ti}_{3} \mathrm{SiC}_{2}$. Variation of friction coefficient of multilayer Ti-Si-C coating (c) and of coatings based on the $M A \mathrm{X}$ phases of $\mathrm{Ti}_{3} \mathrm{SiC}_{2}$ (d) at different loads and rates. (e, f) Respective images of wear tracks after measurement of friction coefficients [numbers correspond to the curves in figures (c) and (d)]. EDS (energy-dispersive X-ray spectroscopy) analysis of a steel ball after testing (g, h) (from Ref. [120]). 

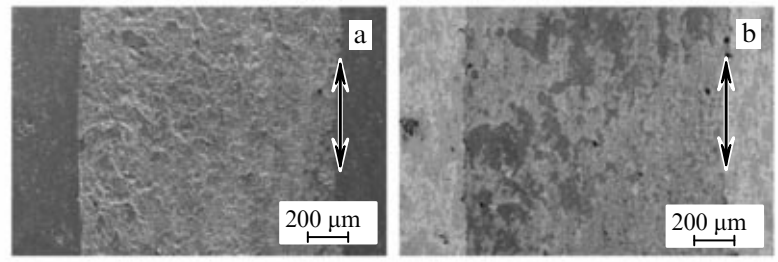

Figure 11. $\mathrm{SEM}$ images of the $\mathrm{Ti}_{3} \mathrm{Si}(\mathrm{Al}) \mathrm{C}_{2} / \mathrm{Ti}_{5} \mathrm{Si}_{3}$ surface after a wearresistance test under $20 \mathrm{~N}$ load obtained with the aid of secondary electrons (a) and back-reflected electrons (b) (from Ref. [132]).

wear. Multilayer Ti-Si-C structures and $M A X$-phases of $\mathrm{Ti}_{3} \mathrm{SiC}_{2}$ exhibited the best characteristics under testing. The friction coefficient after thermal annealing of $\mathrm{Ti}-\mathrm{Si}-\mathrm{C}$ and the formation of the $M A X$-phase of $\mathrm{Ti}_{3} \mathrm{SiC}_{2}$ changed only insignificantly (Fig. 10). For all that, the results of analyses of the wear tracks and the counterbody after testing suggested a less intense transfer of material from the $M A \mathrm{X}$ phase onto the counterbody than from the multilayer coating (Fig. 10e, f).

Tribological tests of epitaxial $\mathrm{Ti}_{3} \mathrm{SiC}_{2}(0001)$ coatings on $\mathrm{Al}_{2} \mathrm{O}_{3}(0001)$ substrates [131] have demonstrated a high abrasive wear rate with a relevant friction coefficient of 0.8 and the generation of wear fragments under large loads (500 and $1000 \mu \mathrm{N})$. Reduced loads $(100-200 \mu \mathrm{N})$ caused neither wear nor deformation, while friction coefficients decreased appreciably to 0.1 due to the absence of $\mathrm{TiO}_{2}$ and carbon in the form of graphite on the coating surface.

Reference [132] demonstrated the possibility of significantly improving tribological characteristics of massive $M A X$-phases through additional doping. For example, doping of $\mathrm{Ti}_{3} \mathrm{Si}(\mathrm{Al}) \mathrm{C}_{2}$ with $\mathrm{Ti}_{5} \mathrm{Si}_{3}$ particles markedly reduced the friction coefficient from 0.75 to 0.6 due to enhanced hardness and the low Young's modulus of the $\mathrm{Ti}_{5} \mathrm{Si}_{3}$ particles in the composite. Dispersed $\mathrm{Ti}_{5} \mathrm{Si}_{3}$ particles (light phase in Fig. 11b) in the $\mathrm{Ti}_{3} \mathrm{Si}(\mathrm{Al}) \mathrm{C}_{2}$ matrix (dark phase in Fig. 11b) efficiently hampered deformation and cracking of the surrounding soft $\mathrm{Ti}_{3} \mathrm{Si}(\mathrm{Al}) \mathrm{C}_{2}$ phase giving rise to elongated planes that overcame load and weakened scratching by the counterbody. The authors of Ref. [132] observed a lowering of the friction coefficient from $0.4-0.5$ to $0.3-0.4$ in an $\mathrm{Al}_{2} \mathrm{O}_{3}$-doped $\mathrm{Ti}_{3} \mathrm{SiC}_{2}$-based composite, whereas a rise in the $\mathrm{Al}_{2} \mathrm{O}_{3}$ content in the composite significantly reduced its wear rate due to the high hardness of $\mathrm{Al}_{2} \mathrm{O}_{3}$ particles surrounded by a relatively soft $M A X$-phase and decentralization of shear stresses under the sliding ball.

$M A X$-phases of Ag-doped $\mathrm{Ta}_{2} \mathrm{AlC}$ and $\mathrm{Cr}_{2} \mathrm{AlC}$ composites are of special interest $[134,135]$. The $\mathrm{Ta}_{2} \mathrm{AlC}$ wear rate at room temperature decreased after Ag doping owing to the emergence of the $\operatorname{Ag}_{2 \pm \delta} \mathrm{Al}$ phase $(\delta \leqslant 0.5)$ at the grain boundaries that prevented the formation of large particles as the result of abrasive wear. In the case of friction under conditions of periodic thermal impact ranging from 26 to $500^{\circ} \mathrm{C}, M A X$-phases of Ag-doped $\mathrm{Ta}_{2} \mathrm{AlC}$ exhibited an adaptive behavior, giving rise to a 'chameleon' two-layer tribofilm (Fig. 12). The outer layer was made up of a mixture of the amorphous oxides $\mathrm{NiO}$ ( $\mathrm{Ni}$ from the counterbody), $\mathrm{Cr}_{2} \mathrm{O}_{3}, \mathrm{FeO}_{1.5-x}, \mathrm{Ta}_{2} \mathrm{O}_{5}, \mathrm{Al}_{2} \mathrm{O}_{3}$, and possibly their solid solutions with the $\mathrm{Ag}_{2} \mathrm{Al}$-based phase. The thicker and less oxidized inner layer consisted of a large amount of carbide (presumably remains of $M A X$-phase grains and binary carbides), besides amorphous oxides and the $\mathrm{Ag}_{2} \mathrm{Al}$ phase. The two layers were strongly bound to each other and to the matrix. Diffuse interlayer boundaries underwent gradient changes in element concentration. The fine structure of amorphous oxides made easier grain boundary sliding at room temperature. The tribological oxidation rate of metals and carbide grains on the surface of the tribofilm was sufficient for the necessary amount of lubricious tribooxides to form even at lower temperatures. Oxidation within tribolayers was rather slow, which accounted for conservation of their microstructure and tribological characteristics. These transformations made it possible for the tribofilms to adapt to the friction process in a wide temperature range (Fig. 12a).

$M A X$-phases of $\mathrm{Ti}_{3} \mathrm{AlC}_{2}$ exhibited an adaptive behavior in a vacuum (from $2 \times 10^{4}$ to $5.0 \mathrm{~Pa}$ ) [136]. In these conditions, the friction coefficient varied between 0.18 and 0.20 , and mild wear was apparent. Testing in the air revealed oxide formation on the rubbing surfaces with the resulting marked increase in the friction coefficient (from 0.18 to 0.7 ) and severe wear of the steel counterbody.

Such behavior of the $M A X$-phases and composites based on them has been thoroughly explored, as demonstrated by the example of compacted massive materials, whereas tribological properties of the respective coatings are poorly known [63, 119]. Analysis of the adaptive behavior of these materials at elevated temperatures confirmed the necessity of further studies on the tribological behavior of $M A X$-phasebased coatings.
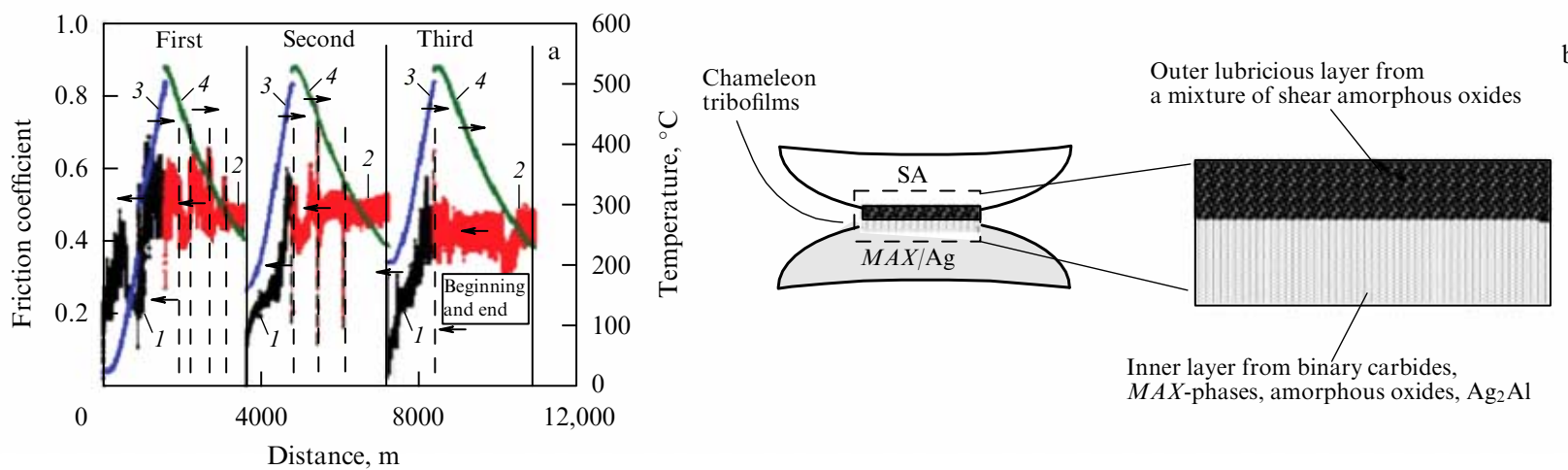

Figure 12. (Color online.) (a) Variation of friction coefficient for a $\mathrm{Ta}_{2} \mathrm{AlC}-\mathrm{Ag} / \mathrm{Inc} 718$ tribological contact (Inc718 - Inconel, a heat-resistant nickelchromium alloy) during heating and cooling in the $26-500{ }^{\circ} \mathrm{C}$ range). Black curve $(I)-$ heating, red curve (2) - cooling, blue curve $(3)-$ heating temperature, green curve (4) — cooling temperature; (b) schematic of a tribofilm formed in a Ta $2 \mathrm{AlC}-\mathrm{Ag} / \mathrm{Inc} 718$ tribological contact (from Refs [133, 134]). 

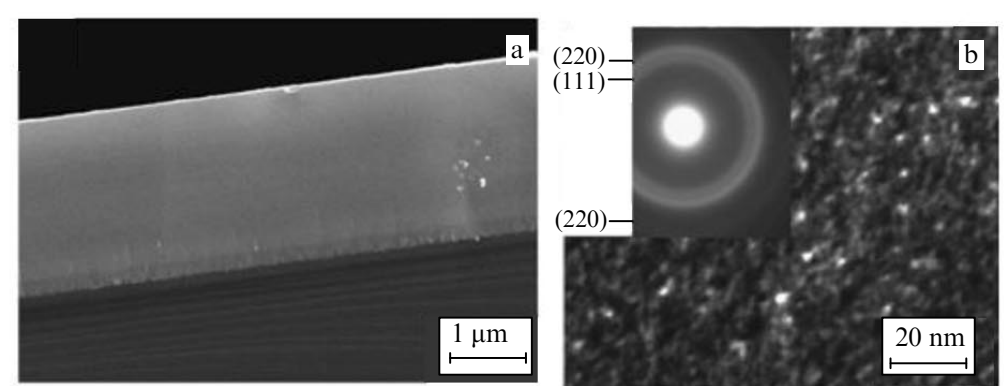

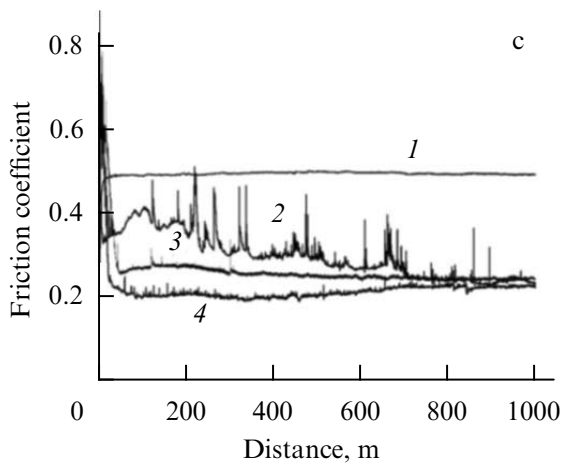

Figure 13. (a) SEM and (b) TEM images of the micro- and nanostructures of single-layer TiCrBN/WSe nanocomposite. (c) Friction coefficient of (1)

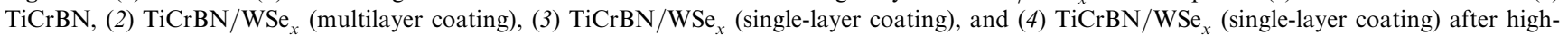
temperature annealing for $1 \mathrm{~h}$ at $500{ }^{\circ} \mathrm{C}$ (from Ref. [151]).

\subsection{Multicomponent and multilayer nanocomposite coatings}

In recent years, multicomponent coatings based on nitrides, borides, and carbides of transition metals with various internal structures have attracted much attention of materials scientists as very promising objects [137-155].

These materials are exemplified by multicomponent TiCrBN/WSe ${ }_{x}$ and TiAlSiCN/MoSeC coatings [15, 152] developed in the group leaded by D V Shtansky. The designers have chosen transition metal carbides and nitrides as the solid phase and used tungsten and molybdenum dichalcogenides, as well as carbon, for improvement of antifriction characteristics. The coatings were synthesized by spraying targets of the desired elemental composition [15, 152].

Structural-phase studies of nanocomposite TiCrBN/WSe ${ }_{x}$ coatings showed that they consist of $\mathrm{TiCrBN}$ with the facecentered cubic (fcc) structure, $\mathrm{WSe}_{2}$, and a-WSe ${ }_{x}$ (Fig. 13a, b). An increase in $\mathrm{WSe}_{x}$ content up to $10 \%$ induced the growth of the amorphous phase and changed the mechanical characteristics of the coating. Specifically, an enhancement of the lubricating phase fraction resulted in a slight decrease in the elasticity modulus (from 320 to $300 \mathrm{GPa}$ ) without altering hardness $(\sim 30 \mathrm{GPa})$; simultaneously, a positive effect on adhesion strength was documented [15, 152]. Results of investigations into friction characteristics are presented in Fig. 13c.

It follows from the above that the addition of the $\mathrm{WSe}_{x}$ phase reduced the friction coefficient in the air from 0.5 to $0.2-0.25$. According to Refs $[15,152]$, the improvement in friction characteristics of the single-layer $\mathrm{TiCrBN} / \mathrm{WSe}_{x}$ coating after high-temperature annealing is due to the presence of two phases, viz. a hard heat-resistant $(\mathrm{Ti}, \mathrm{Cr})(\mathrm{B}, \mathrm{N})$-based phase with grains a few nanometers in size and a mixture $\mathrm{WSe}_{2}+\mathrm{a}-\mathrm{WSe}_{x}$ of intercrystallite phases.

Multicomponent TiAlSiCN/MoSeC coatings were produced by spraying targets with different combinations of segments $\left(\mathrm{MoSe}_{2}+\mathrm{C}\right)$. In the case of TiAlSiCN, an fcc crystal lattice with the predominant (111), (200), and (220) orientation was formed. The TiAlSiCN/MoSEC diffractograms also exhibit reflections corresponding to an fcc crystal lattice, but simultaneously the diffraction lines undergo broadening and displacement toward smaller angles due to a reduced degree of crystallinity and grain size (from 5-15 to $2 \mathrm{~nm}$ ), as was elucidated in Ref. [15].

Results of tribological tests of TiAlSiCN/MoSeC nanocomposites at room temperature are shown in Fig. 14c.
Amorphous TiAlSiCN/MoSeC coatings (Fig. 14a, b) with a highest $\mathrm{MoSeC}$ content exhibited the best adaptive behavior at high temperatures with friction coefficients below 0.1 up to a temperature of $300^{\circ} \mathrm{C}$ (Fig. 14d). The adaptive mechanism was realized through the formation of $\mathrm{MoSe}_{2}$ in the friction contact.

Testing TiAlSiCN coatings in the presence of $\mathrm{Al}_{2} \mathrm{O}_{3}$ and WC - Co balls demonstrated high friction coefficients $(0.95$ and 0.75 , respectively). The authors of Ref. [15] attributed this evidence primarily to the ability of wear products to function as additional abrasives in the friction process. The addition of lubricious phases to the TiAlSiCN coating markedly reduced the friction coefficient from 0.75 to 0.05 . The results of optical profilometry suggested the formation of a thin (up to $50 \mathrm{~nm}$ ) tribolayer on the surface.

Reference [17] presents results of an experimental study on friction and wear mechanisms, as exemplified by multicomponent multilayer TiAlCrYN coatings prepared by successive magnetron sputtering of TiAlCrYN/TiAlCrN, TiAlY(O)NCr(O)N multilayers over steel substrates. Their total thickness was $3.5 \mu \mathrm{m}$ and hardness $26.6 \mathrm{GPa}$, regardless of the type of steel in the substrate. Irregular fluctuations of the friction coefficient are illustrated by the friction curve in Fig. 15.

Testing TiAlCrYN coatings revealed their friction coefficient between 0.61 and 0.68 , or much higher than in another transition metal nitride, TiAlN/VN $(\mu=0.4-0.5)$ [17]. The authors of the last study argue that the friction coefficient decreases as the depth of the nitrided layer increases, with the wear coefficient reaching an extremely high value at a nitriding depth of $270 \mu \mathrm{m}$. Nevertheless, this value is 23 orders of magnitude lower than for nonnitrided steel.

Paper [17] also emphasized the influence of relative humidity of the air on the friction coefficient of TiAlCrYN coatings. The wear coefficient at a relative humidity of 30 $33 \%$ was $\sim 10^{-16} \mathrm{~m}^{3} \mathrm{~N}^{-1} \mathrm{~m}^{-1}$ and significantly increased to $\sim 10^{-15} \mathrm{~m}^{3} \mathrm{~N}^{-1} \mathrm{~m}^{-1}$ as relative humidity fell off.

The tribological film exhibited an amorphous structure apparent in bright-field TEM images of an inclined specimen and in electron diffractograms obtained from a given coating region. TEM-EDX (energy dispersive X-ray analysis) and electron energy loss spectroscopy (EELS) (Fig. 16) gave evidence that an $80-\mathrm{nm}$ thick tribofilm had a compact amorphous structure consisting of a mixture of multicomponent oxides with a common chemical composition of $\mathrm{Cr}_{0.39} \mathrm{Al}_{0.19} \mathrm{Ti}_{0.20} \mathrm{Y}_{0.01} \mathrm{O}_{0.21}$. 

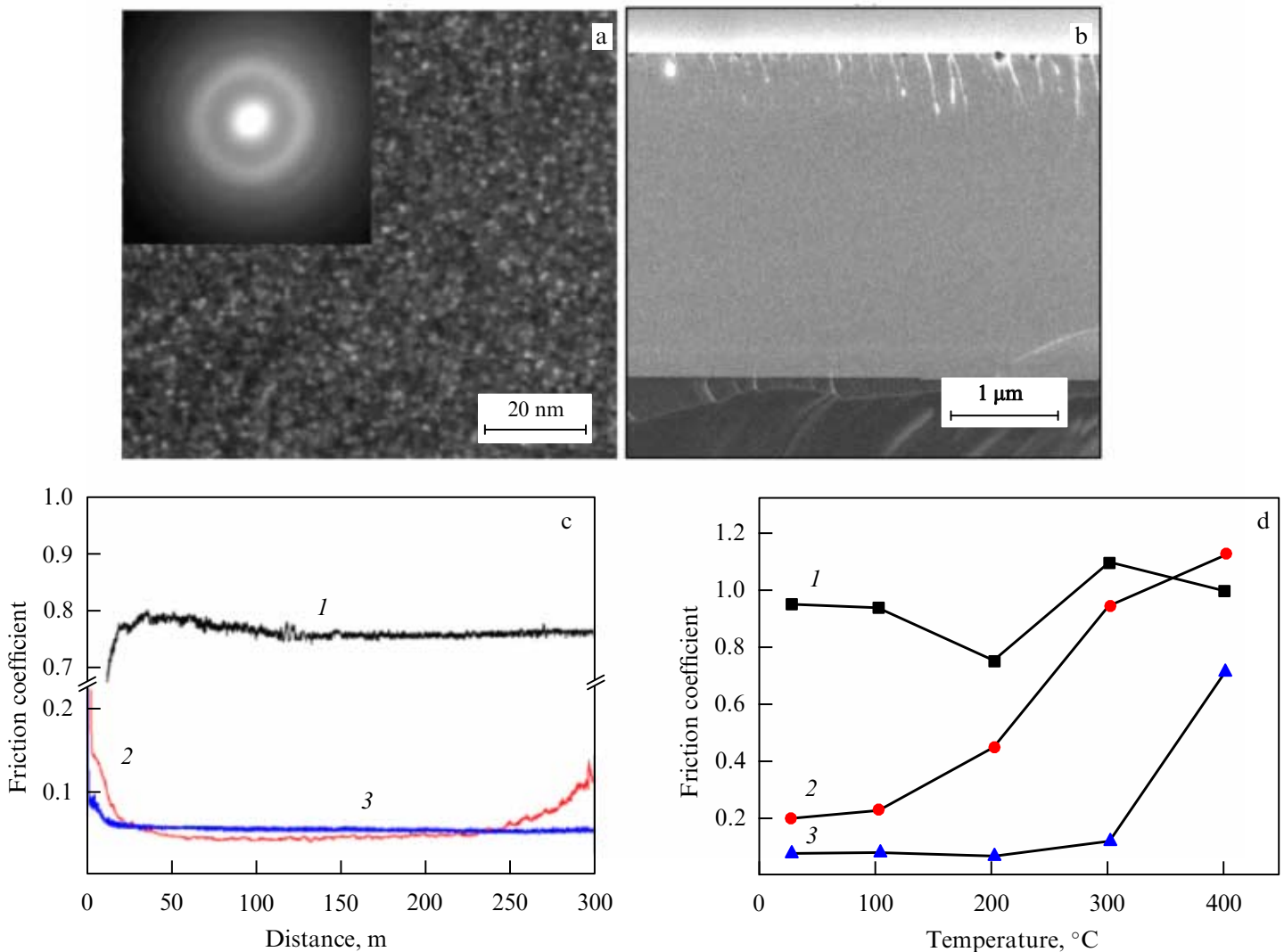

Figure 14. Nano- and microstructures of nanocomposite 0.50TiAlSiCN-0.50MoSeC coating studied by TEM (a) and SEM (b); friction coefficient of TiAlSiCN/MoSeC coatings at different target segment ratios depending on the path length (c) in a temperature range from 25 to $400{ }^{\circ} \mathrm{C}$ (d): $(1)$ TiAlSiCN, (2) 0.75TiAlSiCN-0.25MoSeC, (3) 0.50TiAlSiCN-0.50MoSeC (from Ref. [15]).

The composition of wear fragments actually represented a multicomponent mixture of Ti-Al-Cr-O. EDX and EELS data agree in that they suggest an equally high $\mathrm{O}$ content and low $\mathrm{Cr}$ level; furthermore, they demonstrate a disappearance of the $\mathrm{N}-\mathrm{K}$ spectral line front. These findings led the authors of Ref. [17] to hypothesize a complete tribological oxidation exhausted largely by nitride fragments resulting from mechanical wear.

The results of wear resistance tests of coatings allowed the authors of Ref. [17] to conclude that duplex plasma nitriding processes preceding magnetron sputtering of TiAlCrYN coatings might be instrumental in the improvement of wear

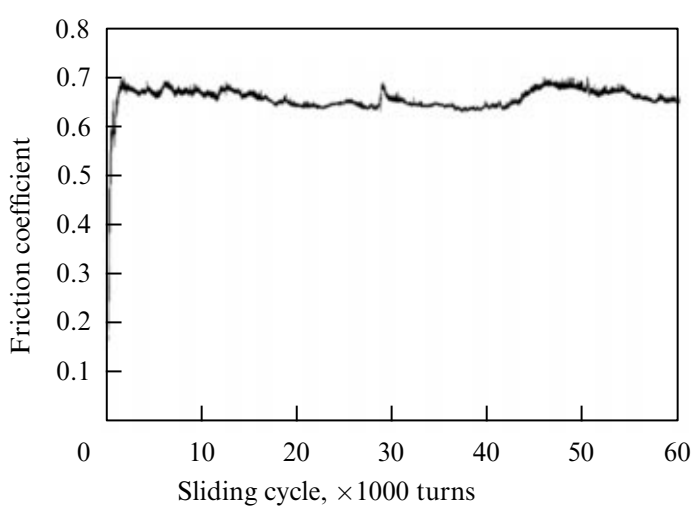

Figure 15. Friction coefficient of TiAlCrYN coating deposited on a P20 steel substrate versus number of repetitions (total sliding distance extended to $4.524 \mathrm{~m}$ ) (from Ref. [17]). resistance of relatively soft surfaces. Moreover, the importance of the run-in period for determining friction coefficients is underscored, bearing in mind their increase during this period and transformation of fragment agglomerates into a tribofilm possessing excellent adhesive properties.

The prevalent chemical bonds in a tribological $\mathrm{Cr}-\mathrm{Ti}-\mathrm{Al}-\mathrm{O}$ film were those linking metal and oxygen atoms, despite the small number of nitrogen atoms. This permits an explanation of the difference among friction coefficients of TiAlCrYN and other coatings with low friction coefficients, such as TiAlN/VN. Because $M-\mathrm{O}$ bonds exhibit stronger shear resistance than $\mathrm{V}-\mathrm{O}$ bonds, TiAlCrYN coatings containing $\mathrm{Cr}-\mathrm{O}, \mathrm{Al}-\mathrm{O}$, and $\mathrm{Ti}-\mathrm{O}$ bonds demonstrate higher friction coefficients.

Raman spectra have revealed (from closeness of relevant spectra) the presence of an $\alpha-\mathrm{Al}_{2} \mathrm{O}_{3}$ phase in both wear fragments and tribological films [17]. These spectral shifts did not correspond to other related oxides, such as rutile and anatase, presumably because the wear fragments and tribological films were multicomponent in amorphous, as well as in nanocrystalline, states. Evidently, the Raman peaks from short-range order structures must be different from standard (crystalline) oxide peaks; in other words, a marked broadening of vibrational bands should be expected. A comparison of the Raman spectra gave reason to conclude that the difference between vibrational lines of the coating and wear fragments is due to the distinction in chemical bonds between the nitride coating and wear products, arising in tribochemical reactions. The interatomic chemical bonds and the nanostructure of materials govern their mechanical behavior. 

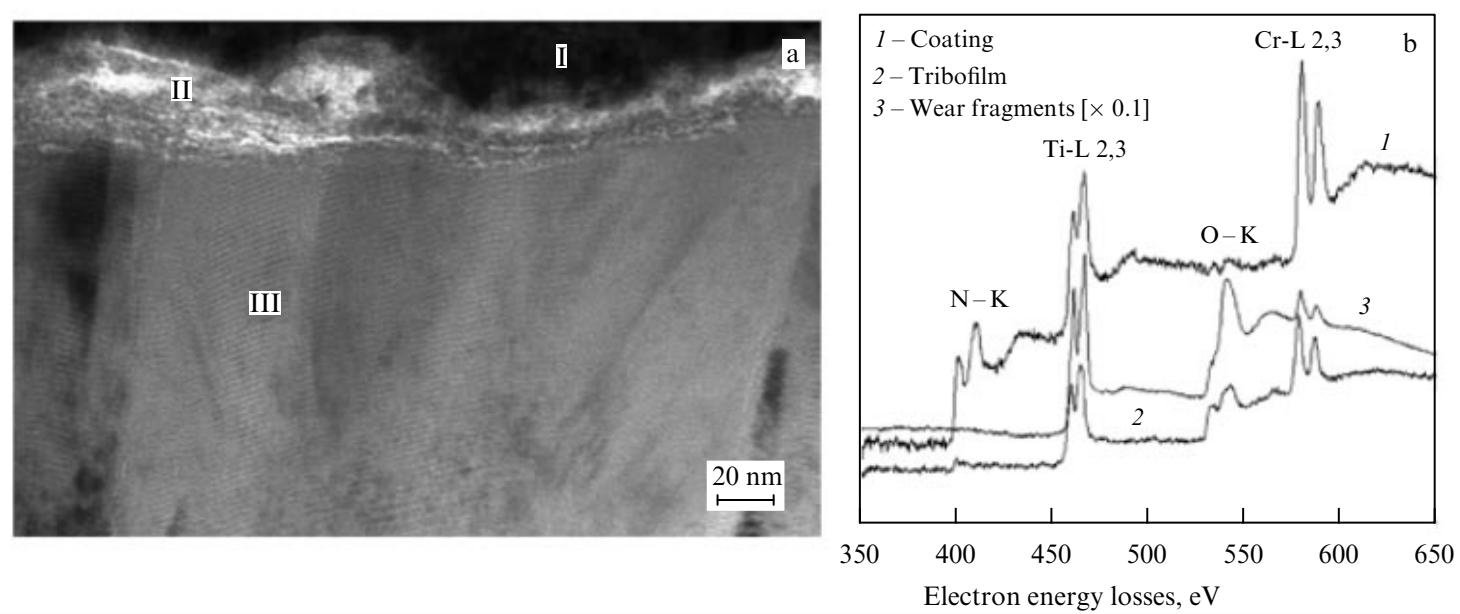

Figure 16. TEM image of the surface of a multilayer TiAlCrYN coating after the wear-resistance test (a) and characteristic electron energy loss spectroscopy of a TiAlCrYN coating, a tribofilm, and wear fragments (b). I, II, III in figure (a) denote copper deposit, tribofilm, and TiAlCrYN coating, respectively (from Ref. [17]).

Service characteristics of nanocomposite TiAlCrYN coatings having an $\mathrm{NaCl}$ type nanocolumnar structure (Fig. 17) were reported in Ref. [12]. The grain size was 5.6, 8.2, and $7.3 \mathrm{~nm}$ in series 1, 2, and 3 coatings, respectively (Figs 17a-c).

The adhesive strength of TiAlCrYN coatings was studied in Ref. [12] using a nanoscratch tester. Eight tests were carried out for each coating. The strain depth and friction coefficient increased during loading with increasing normal load. Both the indentation depth and the friction coefficient were sharply enhanced under a load of $374 \mathrm{mN}$ (Fig. 18). The authors referred to this load as critical (the moment the first chevron crack appeared) and denoted it by $L_{\mathrm{c}_{L}}$. The coating was partly detached at this point and its failure was due to the high compressive stress exerted by the indenter. The post-scan profile gave evidence that coating failure occurred under a subcritical load. The load at the failure point was denoted by $L_{\mathrm{c}_{U}}$. Bull et al. $[156,157]$ argue that the failure is a result of asynchronous recovery of strain between the coating and the substrate that causes shear stress along the transition layer and leads to a split in the coating. The critical load values suggest that series 3 specimens (Fig. 18c) possess a higher adhesive strength than do series 1 and 2 specimens (Fig. 18a, b).

Optical images of the wear tracks after the scratch test (Figs 18d-f) clearly demonstrate splitting after high compressive stress produced by an indenter and reverse elastic splitting under a relatively small load. These effects are attributable to wedge-shaped splitting in the form of semicircular cracks spreading outward from the central scratch track. All coatings were partly detached after critical loading. Optical images confirm the improved adhesive strength of series 3 coatings compared with those from series 1 and 2 specimens.

Wear-resistance tests of TiAlCrYN coatings were conducted using a CETR UMT-2 microtribometer at room temperature with a stainless steel counterbody under a $2 \mathrm{~N}$ load. Series 1, 2, and 3 specimens had average friction coefficients of $0.68,0.78$, and $0.7-0.73$, respectively. The authors of Ref. [12] also observed signs of microwear and oxidation of the worn out coating with the formation of a thin oxide layer and free wear fragments of this oxide. Neither cracks nor destructive detachments were apparent, which suggested a high resistance strength in these coatings.
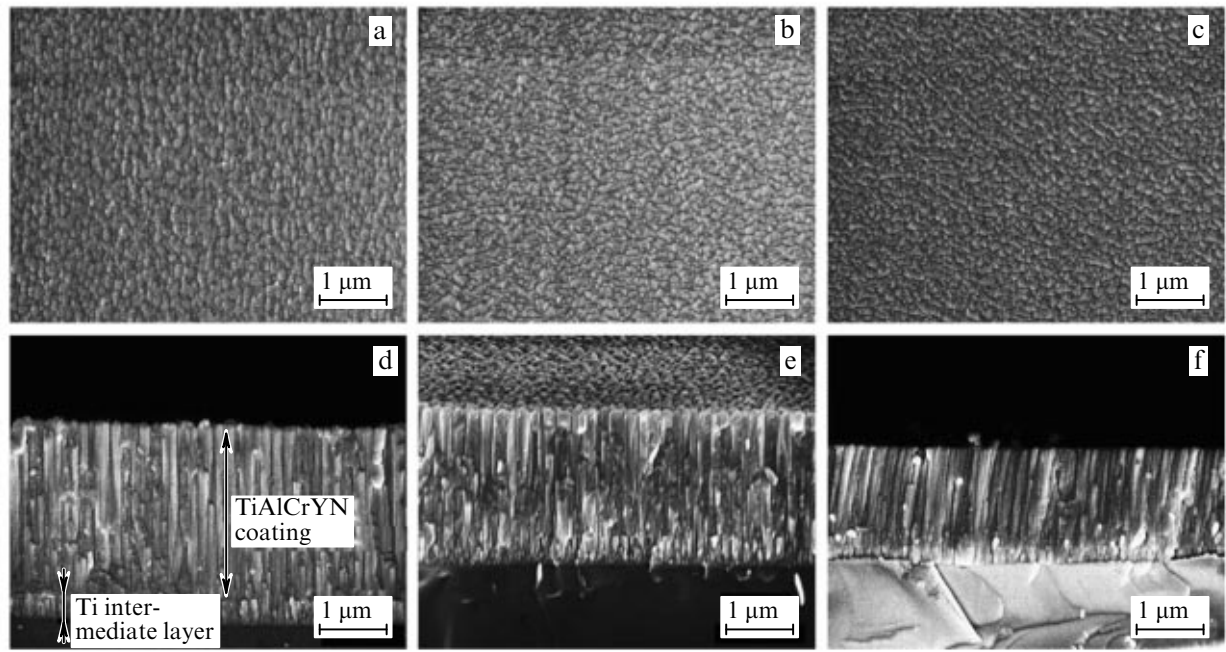

Figure 17. SEM images of series 1, 2, and 3 TiAlCrYN coating surfaces (a-c) and their cross sections (d-f) (from Ref. [12]). 

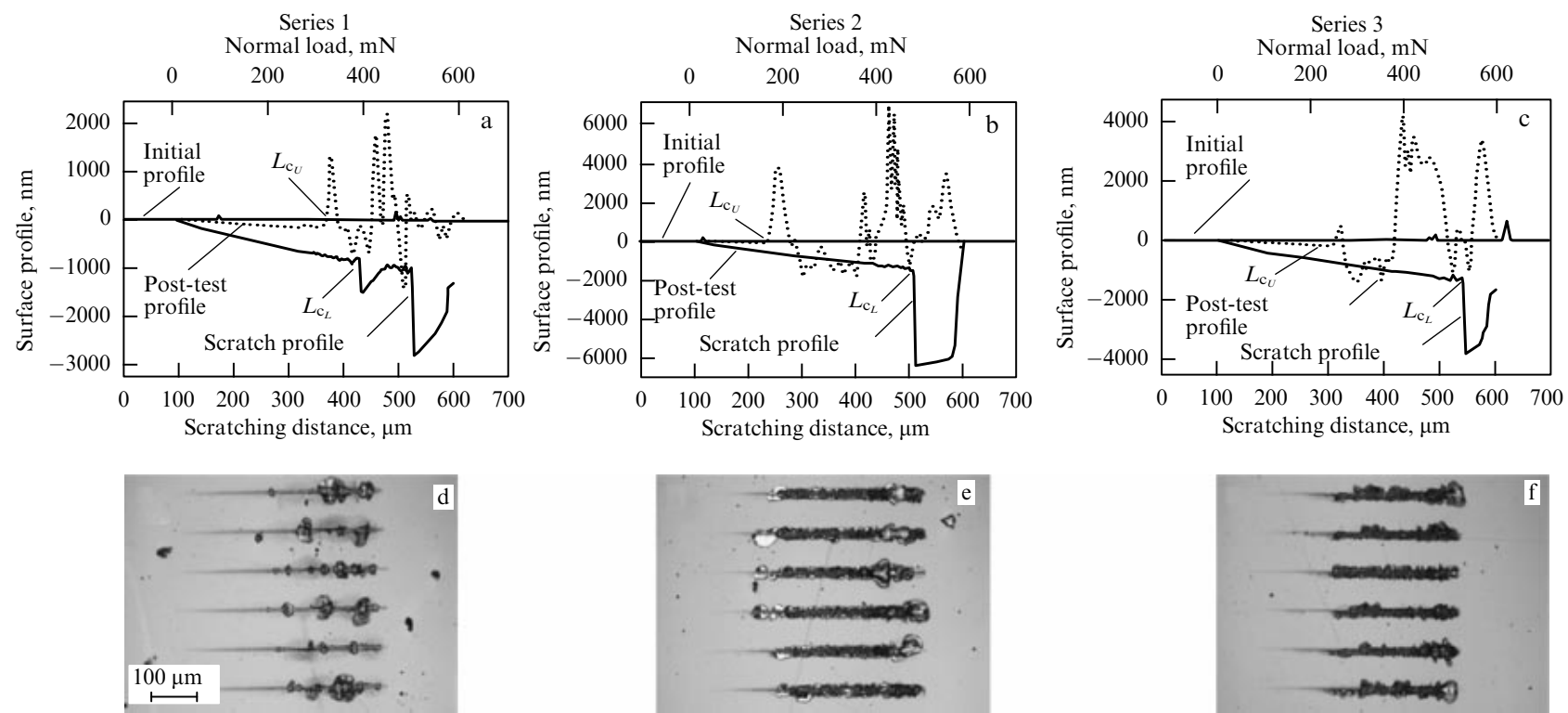

Figure 18. (a-c) Typical profiles of nanoscratch tests and friction for series 1, 2, and 3 specimens. (d-f) Optical microphotographs of scratch tracks under $600 \mathrm{mN}$ for series 1, 2, and 3 specimens, respectively (from Ref. [12]).

A D Pogrebnjak, V M Beresnev et al. [158] reported results of investigations of multilayer $\mathrm{Ti}-\mathrm{Hf}-\mathrm{Si}-\mathrm{N} / \mathrm{NbN} /$ $\mathrm{Al}_{2} \mathrm{O}_{3}$ coatings obtained by cathodic vacuum-arc deposition with HF stimulation. The coating had a hardness of 47.856.5 $\mathrm{GPa}$ and elastic modulus ranging 435-578 GPa. The authors emphasized that hardness increased closer to the transient zone. The friction coefficient of this multilayer coating was initially 0.02 and decreased to 0.001 in the course of testing. The parameters of deposition influenced the elemental distribution over concentration in the coating and thereby its mechanical properties.

Reference [159] reports an evaluation of the dependence of mechanical and tribological properties of nanocomposite TiAlSiCuN coatings on silicon concentration (Fig. 19). An XRD analysis [159] showed that coatings of different stoichiometries $\left(\mathrm{Ti}_{0.54} \mathrm{Al}_{0.42} \mathrm{Si}_{0.01} \mathrm{Cu}_{0.03} \mathrm{~N}, \quad \mathrm{Ti}_{0.43} \mathrm{Al}_{0.48} \mathrm{Si}_{0.06} \mathrm{Cu}_{0.03} \mathrm{~N}\right.$, and $\mathrm{Ti}_{0.45} \mathrm{Al}_{0.42} \mathrm{Si}_{0.10} \mathrm{Cu}_{0.03} \mathrm{~N}$ ) consisted of the nanocrystalline Ti-Al-N phase and $\mathrm{Cu}$, while the $\mathrm{Si}_{3} \mathrm{~N}_{4}$ phase had either an amorphous or silicon-like structure. The authors arrived at
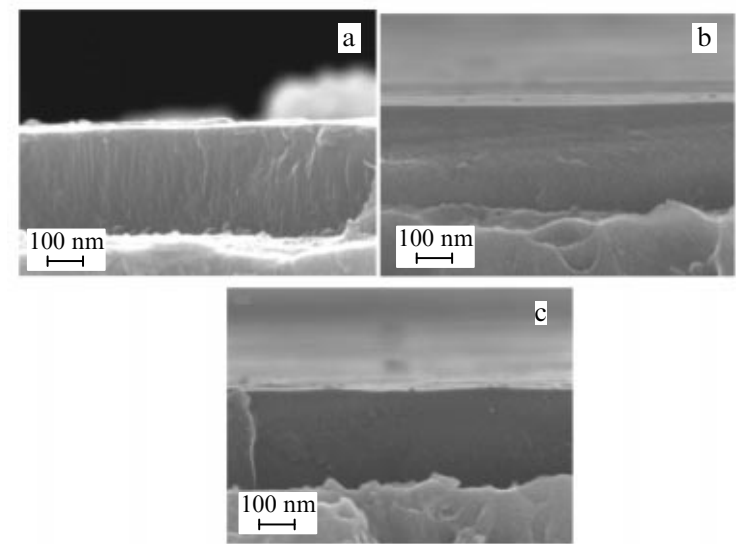

Figure 19. SEM images of cross sections of nanocomposite coatings $\mathrm{Ti}_{0.54} \mathrm{Al}_{0.42} \mathrm{Si}_{0.01} \mathrm{Cu}_{0.03} \mathrm{~N} \quad$ (a), $\mathrm{Ti}_{0.43} \mathrm{Al}_{0.48} \mathrm{Si}_{0.06} \mathrm{Cu}_{0.03} \mathrm{~N} \quad$ (b), and $\mathrm{Ti}_{0.45} \mathrm{Al}_{0.42} \mathrm{Si}_{0.10} \mathrm{Cu}_{0.03} \mathrm{~N}$ (c) (from Ref. [160]). the following conclusions based on the results of XRD and XPS (X-ray photoelectron spectroscopy) analyses [159]:

- $\mathrm{Ti}_{0.54} \mathrm{Al}_{0.42} \mathrm{Si}_{0.01} \mathrm{Cu}_{0.03} \mathrm{~N}$ nanofilms make up coatings containing a solid solution;

- segregation of Ti-Al-Si-N nanocrystals in an amorphous $\mathrm{Si}_{3} \mathrm{~N}_{4}$ matrix results in the formation of an nc-TiAlN/ $\mathrm{Si}_{3} \mathrm{~N}_{4}$ type nanocomposite film in both $\mathrm{Ti}_{0.43} \mathrm{Al}_{0.48} \mathrm{Si}_{0.06} \mathrm{Cu}_{0.03} \mathrm{~N}$ and $\mathrm{Ti}_{0.45} \mathrm{Al}_{0.42} \mathrm{Si}_{0.10} \mathrm{Cu}_{0.03} \mathrm{~N}$ coatings.

The evolution of the friction coefficient in a TiAlSiCuNbased coating for an Si concentration range of 0-5.09 at. \% is illustrated in Fig. 20. In Si-free coatings, the friction coefficient increased within the first $7 \mathrm{~min}$ of the test owing to low hardness of the material; thereafter, it remained at a level of $0.8-0.9$, suggesting intense adhesive and abrasive wear. The addition of $\mathrm{Si}$ into the coating and a further increase in its concentration caused a gradual decrease in the friction coefficient to $0.9,0.8$, and 0.7 at $1.44,3.39$, and 5.09 at. $\% \mathrm{Si}$, respectively, due to diminishing surface roughness with increasing Si content.

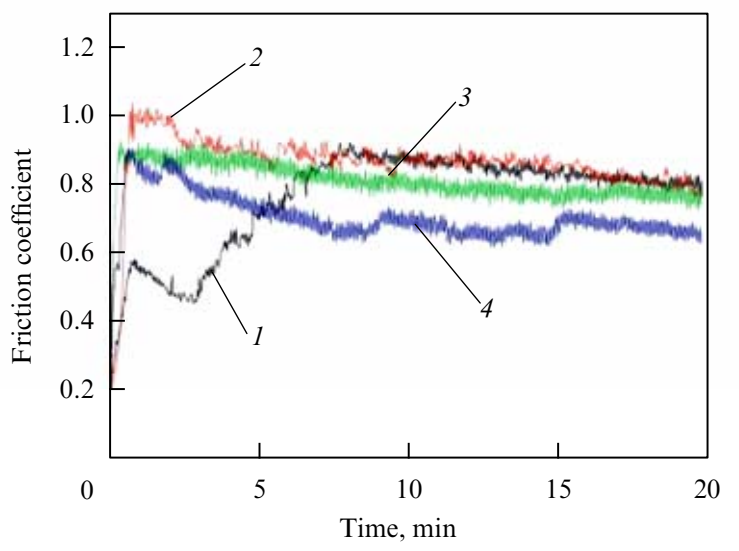

Figure 20. Friction coefficient of TiAlN/ $\mathrm{Si}_{3} \mathrm{~N}_{4}-\mathrm{Cu}$ coatings with various Si contents: 0 at.\% (1), 1.44 at.\% (2), 3.39 at.\% (3), and 5.09 at.\% (4) (from Ref. [160]). 

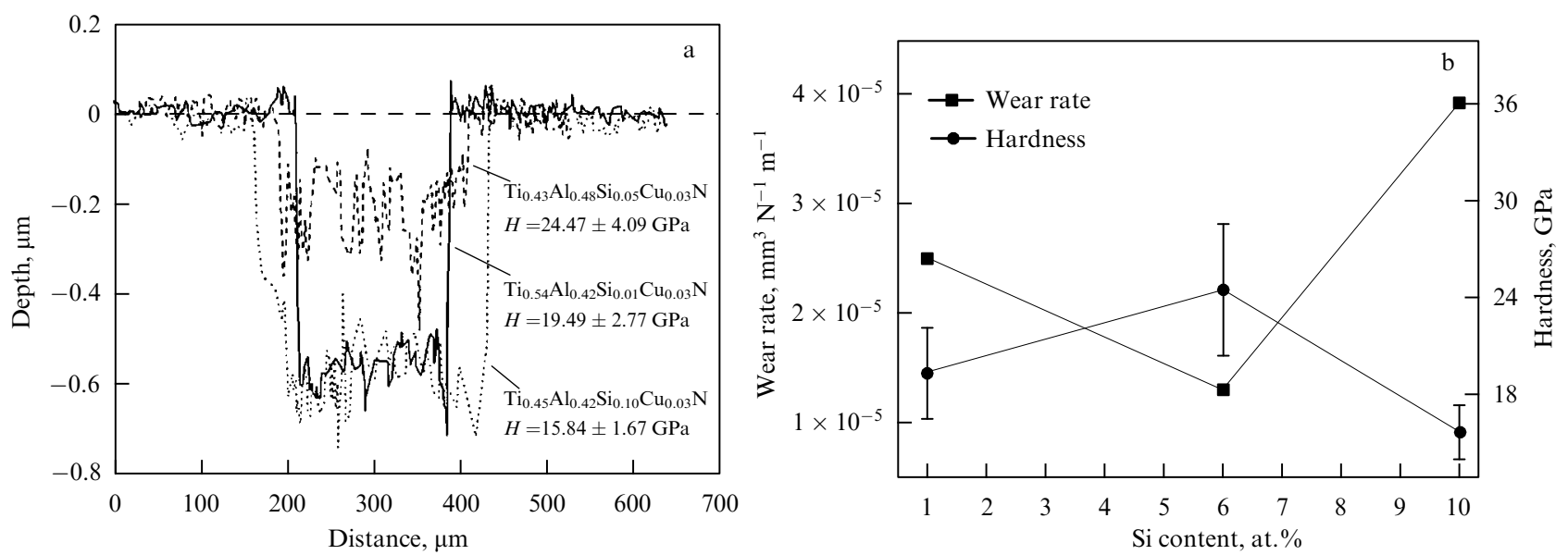

Figure 21. (a) Wear track depth profiles of Ti-Al-Si-Cu-N nanofilms under a load of $5 \mathrm{~N}$. (b) Wear rate and hardness as a function of Si concentration (from Ref. [159]).

Results of the study of wear tracks and EDS analysis of wear fragments enabled the authors of paper [160] to conclude that the wear mechanism of coatings containing 5.09 at. $\% \mathrm{Si}$ includes abrasive, adhesive, and corrosive constituents. Such coatings have the poorest adhesion to the substrate, which accounts for their detachment during testing. Coatings with 3.39 at. \% Si are characterized by the predominantly adhesive wear mechanism, with the low friction coefficient being due to the influence of combined lubrication of a softer copper phase and iron oxide, as well as to the decreasing grain size (Fig. 21). Coatings containing 1.44 at. $\% \mathrm{Si}$ are subject to abrasive wear. A common feature of all the above coatings is that their wear fragments are largely $\mathrm{Ti}, \mathrm{Al}$, and $\mathrm{O}$.

Reference [54] describes a hard multilayer TiAlCrSiYN coating showing an adaptive behavior under extreme tribological conditions (dry ultrahigh-speed machining of hardened steel). The main feature of this coating is the

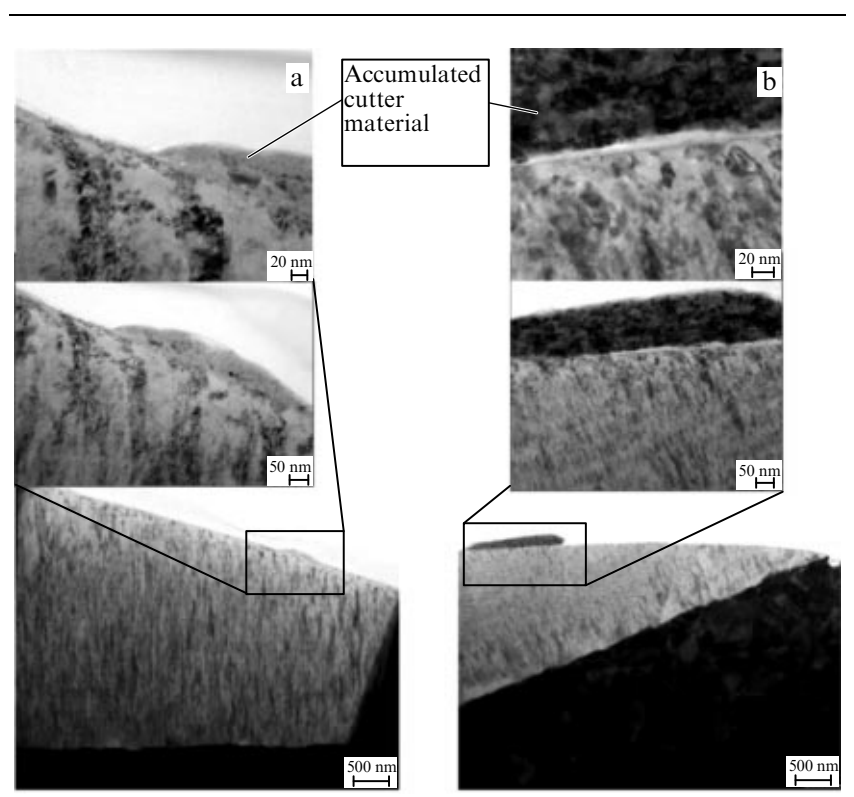

Figure 22. TEM image of a worn-out ball cutter coated with a TiAlCrSiYN single-layer (a) and a multilayer TiAlCrSiYN/TiAlCrN coating (b) (from Ref. [54]). formation of a nano-scale protective tribofilm through selforganization in the friction process (Figs 22a, b). Improved operational characteristics of the TiAlCrSiYN/TiAlCrN coatings are due to a tendency toward the formation of a protective tribological sapphire- and mullite-based film. Such a surface film prevents heat penetration into the bulk of the coating and thereby markedly slows down not only its failure but also the generation of undesirable ( $\left(\mathrm{AlN}_{\mathrm{hex}}\right)$ phases.

The hardness of multilayer TiAlCrSiYN/TiAlCrN coatings is constant $(27 \mathrm{GPa})$ at temperatures up to $500^{\circ} \mathrm{C}$. It slightly decreases at $600^{\circ} \mathrm{C}$ but remains high $(22 \mathrm{GPa})$ thereafter. In contrast, single-layer TiAlCrSiYN coatings gradually soften with temperature. The stable high-temperature hardness of TiAlCrSiYN/TiAlCrN coatings may be due to the obstacles encountered by dislocations during their propagation through layer/layer interfaces in loaded nanomultilayer coatings [54]. In addition, multilayer TiAlCr$\mathrm{SiYN} / \mathrm{TiAlCrN}$ coatings also show higher loading resistance (plastic strain resistance defined by the ratio $H^{3} / E_{\mathrm{r}}^{2}$ [54], where $H$ is the hardness, and $E_{\mathrm{r}}$ is the modulus of elasticity), especially at elevated temperatures. This parameter is fairly well correlated with fatigue failure resistance [54]. It can be concluded that the adaptive mechanism in a multilayer coating is realized via formation of a protective tribological film on the coating surface during its exploitation, which enables the coating to sustain enhanced loading at high temperatures.

Multilayer coatings exhibit enhanced resistance to fatigue failure. Regions exposed to $150 \mathrm{mN}$ have better operating characteristics due to higher loading resistance [61]. This reduces to a minimum the probability of a cracking origin, decreases damage to the surface, and improves wear resistance [47].

Rapid failure is characteristic of a single-layer $\mathrm{Ti}_{0.2} \mathrm{Al}_{0.55} \mathrm{Cr}_{0.2} \mathrm{Si}_{0.03} \mathrm{Y}_{0.02} \mathrm{~N}$ coating. In contrast, cracks in multilayer $\quad \mathrm{Ti}_{0.2} \mathrm{Al}_{0.55} \mathrm{Cr}_{0.2} \mathrm{Si}_{0.03} \mathrm{Y}_{0.02} \mathrm{~N} / \mathrm{Ti}_{0.25} \mathrm{Al}_{0.65} \mathrm{Cr}_{0.1} \mathrm{~N}$ coatings reflect from the nanolayered structure [161]. This energy dissipation mechanism in multilayer coatings was investigated by TEM in Ref. [162]. Cracks in multilayer coatings resulted from damages to the surface by friction and intense thermomechanical processing. 


\section{Conclusion}

This review deals with physical aspects of designing multielement and multilayer nanostructures with reference to hypotheses and ideas from various natural sciences, including solid state and plasma physics, materials engineering, physical chemistry, and condensed matter and consolidated material physics [163-177].

Modern adaptive wear-resistant coatings can be regarded as hierarchical nanostructural materials of surface engineering. They are characterized by a dynamic hierarchy at two main structural levels: nano-scale layers of tribofilm surfaces perform a protective lubricating function, serve as a thermal barrier, and control wear resistance of the entire surfaceengineering system, and nano/microlaminate coatings having a complicated nanocrystalline/multilayer structure and a nonequilibrium state.

Nanostructural states arise in highly nonequilibrium solid bodies near the zero Gibbs thermodynamic potential and are pre-transition structural-phase states in which nanocrystals and the quasiamorphous phase coexist. The stability of nanostructural states is determined by entropy production associated with the expansion of the crystal molar volume up to the critical values near the structural-phase crystal-toquasiamorphous medium transition.

The formation of nanostructural states in the entire volume of a solid body in response to high-energy exposure is accompanied by its dispersion with the formation of nanoparticles possessing a quasiamorphous shell. A consolidated nanostructure can be created and conserved either in hydrostatic compression fields with a shear or in the surface layer of a solid body, taking advantage of thermodynamic stability of the submicrocrystalline substrate.

Adaptive wear resistance coatings fully realize their potential under extreme tribological conditions characterized primarily by strong gradients of various characteristics on rubbing surfaces. They are far from equilibrium state and have a very high wear rate of unprotected surface sites during friction.

The main feature of adaptive hierarchical surface type nanomaterials is the formation of various nano-scale tribological films on the coating surface by means of self-organization during friction. The formation is a result of structural modification of the engineering material surface and its interaction with environmental factors (first and foremost oxygen from the air) that leads to tribological oxidation under strong loading and high temperature.

Special attention is given to a new line of nanomaterials research, namely compositional and structural optimization of surface tribofilms by adjusting hard adaptive coatings designed for concrete applications.

The review summarizes the results of long-term investigations into the characteristics of tribological films. Thermodynamic analysis has demonstrated that the formation of tribofilms is a highly nonequilibrium process associated with decreased entropy production and high energy consumption. A tribological system, therefore, absorbs energy that can damage the surface and thereby markedly heightens the wear rate. As dissipative structures, tribofilms possess certain characteristics crucial for meeting various operational conditions by maintaining excellent protective and/or lubricating properties of the frictional surface. Another important feature of adaptive coatings with an enhanced ability to form protective and/or lubricious tribofilms is their improved thermal behavior responsible for creating the large temperature gradient at the tool/chip boundary and reduced overheating of the coated instrument. Concentration of most of the interaction energy between rubbing bodies proceeds in thin nano-scale layers of tribological films, thus reducing damage to the coated surface, which explains why adaptive coatings withstand severe climatic conditions.

Control of the structure and properties of nano-scale tribological films for optimizing the characteristics of adaptive coatings should be an important component of further theoretical and experimental studies.

\section{Acknowledgments}

This work was performed in the framework of budgetary projects of the Ukrainian Ministry of Education and Science: No. 115U000682, "Development of materials science principles of structural engineering of superhard vacuum-plasma coatings with desired functional characteristics"; No. 0116U002621, "Physical basis for the formation of composition and properties of nanostructural boride, nitride, and boride-nitride films of transition metals for applications in the machine-building industry", and No. 0116U006816, "Development of new perspective nanostructural multilayer coatings with improved physico-mechanical and tribological properties".

\section{References}

1. Azarenkov N A et al. Nanostrukturnye Pokrytiya i Nanomaterialy: Osnovy Polucheniya, Svoistva, Oblasti Primeneniya. Osobennosti Sovremennogo Nanostrukturnogo Napravleniya $v$ Nanotekhnologii (Nanostructural Coatings and Nanomaterials: Principles of Production, Properties and Areas of Application. Modern Nanostructural Aspects of Nanotechnology) (Moscow: Librokom, 2013)

2. Rebholz C et al. Surf. Coat. Technol. 113126 (1999)

3. Rebholz C et al. Surf. Coat. Technol. 116-119 648 (1999)

4. Pogrebnjak A D et al. Phys. Usp. 5229 (2009); Usp. Fiz. Nauk 17935 (2009)

5. Pogrebnjak A D, Beresnev V M Nanocoatings, Nanosystems, Nanotechnologies (Sharjah: Bentham Science Publ., 2012)

6. Veprek S J. Vac. Sci. Technol. A 3146 (2014)

7. Korotaev A D et al. Fiz. Mezomekh. 8 (5) 103 (2005)

8. Musil J Physical and Mechanical Properties of Hard Nanocomposite Films Prepared by Reactive Magnetron Sputtering (New York: Springer, 2006)

9. Pogrebnjak A D, Yakushchenko I V, Bagdasaryan A A et al. Mat. Chem. Phys. 1471079 (2014)

10. Tyurin Yu N, Pogrebnjak A D Surf. Coat. Technol. 111269 (1999)

11. Vereshchaka A A et al. Proc. CIPR 14239 (2014)

12. Barshilia H C, Acharya S, Ghosh M Vacuum 85411 (2010)

13. Faga M G et al. Wear 2631306 (2007)

14. Drory M D, Evans R D Surf. Coat. Technol. 2061983 (2011)

15. Bondarev A V et al. Appl. Surf. Sci. 327253 (2015)

16. Oeztuerk A et al. Tribol. Int. 4149 (2008)

17. Luo Q et al. Tribol. Lett. 34113 (2009)

18. Pogrebnjak A D et al. Acta Phys. Polon. A 123816 (2013)

19. Sobol O V, Pogrebnjak A D, Beresnev V M Phys. Met. Metallurg. 112118 (2011)

20. Grigoriev S N et al. J. Friction Wear 35359 (2014)

21. Veprek S, Veprek-Heijman M G J Thin Solid Films 522274 (2012)

22. Gershman J S, Bushe N A Surf. Coat. Technol. 186405 (2004)

23. Chang Y-Y, Hsiao C-Y Surf. Coat. Technol. 204992 (2009)

24. Dubrovinskaia N et al. Appl. Phys. Lett. 90101912 (2007)

25. Lewis D B et al. Surf. Coat. Technol. 114187 (1999)

26. Lin J et al. Acta Mater. 581554 (2010)

27. AL-Bukhaitia M A et al. Appl. Surf. Sci. 318180 (2014)

28. Lin S Trans. Nonferrous Met. Soc. China 25451 (2015)

29. Beliardouh N E et al. Tribol. Int. 82443 (2015)

30. Liew W Y H et al. Proc. Eng. 68512 (2013)

31. Wu M-K, Lee J-W, Chan Y-C Surf. Coat. Technol. 2061886 (2011) 
32. Holmberg K et al. Surf. Coat. Technol. 2021034 (2007)

33. Ivashchenko V et al. Sci. Technol. Adv. Mater. 15025007 (2014)

34. Houska J, Klemberg-Sapieha J E, Martinu L Surf. Coat. Technol. 2033348 (2009)

35. Zhao X, Xie Z, Munroe P Mater. Sci. Eng. A 5281111 (2011)

36. Pogrebnjak A D et al. Acta Phys. Polon. A 1251284 (2014)

37. Pogrebnjak A D et al. Phys. Solid State 571559 (2015); Fiz. Tverd. Tela 571529 (2015)

38. Pogrebnjak A D et al. Tech. Phys. 601176 (2015); Zh. Tekh. Fiz. 85 (8) 72 (2015)

39. Musil J Surf. Coat. Technol. 20750 (2012)

40. Gissler W Surf. Coat. Technol. 68-69556 (1994)

41. Vepřek S Surf. Coat. Technol. 9715 (1997)

42. Mitterer C et al. Vacuum 50313 (1998)

43. Noli F et al. Appl. Surf. Sci. 2528043 (2006)

44. Pogrebnjak A D et al. Int. J. Ref. Met. Hard. Mater. 48222 (2015)

45. Danilchenko S N et al. Cryst. Res. Technol. 41268 (2006)

46. Pichugin V F et al. J. Surf. Investig. X-Ray Synchrotron Neutron Tech. 10282 (2016)

47. Zabinski J S et al. Thin Solid Films 214156 (1992)

48. Zabinski J S, Donley M S, US Patent No. 5282985 (1994)

49. Voevodin A A, Zabinski J S Thin Solid Films 370223 (2000)

50. Inoue $\mathrm{S}$ et al. Thin Solid Films 300171 (1997)

51. Musil J Surf. Coat. Technol. 125322 (2000)

52. Bhushan B Phil. Trans. R. Soc. A 3661351 (2008)

53. Paternoster C et al. Surf. Coat. Technol. 203736 (2008)

54. Fox-Rabinovich G S et al. J. Appl. Phys. 111064306 (2012)

55. Voevodin A A et al. (Eds) Nanostructured Thin Films and Nanodispersion Strengthened Coatings (NATO Science Series, II, Vol. 155) (Dordrecht: Kluwer Acad., 2004)

56. Voevodin A A et al. J. Vac. Sci. Technol. A 201434 (2002)

57. Holmberg K, Matthews A Coatings Tribology: Properties, Mechanisms, Techniques and Applications in Surface Engineering (Amsterdam: Elsevier Science, 2009)

58. Muratore C, Hu J J, Voevodin A A Thin Solid Films 5153638 (2007)

59. Aouadi S M et al. Surf. Coat. Technol. 204962 (2009)

60. Stone D S et al. Surf. Coat. Technol. 2064316 (2012)

61. Donnet C, Erdemir A Surf. Coat. Technol. 180-181 76 (2004)

62. Voevodin A A, Zabinski J S, Muratore C Tsinghua Sci. Technol. 10 665 (2005)

63. Voevodin A A, Muratore C, Aouadi S M Surf. Coat. Technol. 257 247 (2014)

64. Pogrebnjak A D et al. Russ. Chem. Rev. 821135 (2013); Usp. Khim. 821135 (2013)

65. Goncharov A A Phys. Solid State 50168 (2011); Fiz. Tverd. Tela 50 163 (2008)

66. Musil J RSC Adv. 560482 (2015)

67. Pogrebnjak A D, Tolopa A M Nucl. Instrum. Meth. Phys. Res. B 52 25 (1990)

68. Pogrebnjak A D et al. Nucl. Instrum. Meth. Phys. Res. B 145373 (1998)

69. Pogrebnjak A D, Ivasishin O M, Beresnev V M Usp. Fiz. Met. 171 (2016)

70. Gleiter H Acta Mater. 481 (2000)

71. Panin V E, Egorushkin V E Fiz. Mezomekh. 11 (2) 9 (2008)

72. Panin V E, Egorushkin V E Fiz. Mezomekh. 12 (4) 7 (2009)

73. Adachi M, Lockwood D J (Eds) Self-Organized Nanoscale Materials (New York: Springer, 2006)

74. Feistel R, Ebeling W Physics of Self-Organization and Evolution (Weinheim: Wiley-VCH, 2011)

75. Haken H Information and Self-Organization: a Macroscopic Approach to Complex Systems (Berlin: Springer, 2006)

76. Olemskoi A I, Khomenko A V Sinergetika Kondensirovannoi Sredy (Synergetics of Condensed Medium) (Sumy: SumGU, 2002)

77. Fox-Rabinovich G S et al. Entropy 12275 (2010)

78. Fox-Rabinovich G S et al. Lubricants 2113 (2014)

79. Fox-Rabinovich G S, Totten G E (Eds) Self-Organization During Friction: Advanced Surface-Engineered Materials and Systems Design (Boca Raton, FL: CRC, Taylor and Francis, 2007)

80. Fox-Rabinovich G S, Wang Q J, Chung Y W Adaptive Hard Coatings Design Based on the Concept of Self-Organization During Friction (London: Springer, 2013)
81. Gershman I S et al. "Elements of thermodynamics and selforganization during friction", in Self-Organization during Friction. Advanced Surface-Engineered Materials and Systems Design (Eds G S Fox-Rabinovich, G E Totten) (Boca Raton, FL: CRC, Taylor and Francis, 2006)

82. Gershman I S Trenie Iznos Smazka 871 (2006)

83. Beake B D et al., in Self-Organization During Friction. Advanced Surface-Engineered Materials and Systems Design (Eds G S FoxRabinovich, G E Totten) (Boca Raton, FL: CRC, Taylor and Francis, 2006)

84. Kostetskii B I, Nosovskii M G, Bershadskii L I Poverkhnostnaya Prochnost' Materialov pri Trenii (Surface Strength of Materials During Friction) (Kiev: Tekhnika, 1976)

85. Gershman I S, Chertovskikh S V, Shuster L Sh Izv. Samarskogo Nauchn. Tsentra Ross. Akad. Nauk 13999 (2011)

86. Bershadskii L I Strukturnaya Termodinamika Tribosistem (Structural Thermodynamics of Tribological Systems) (Kiev: Znanie, 1990)

87. Gershman J S, Bushe N A Surf. Coat. Technol. 186405 (2004)

88. Migranov M Sh, Shuster L Sh Izv. Samarskogo Nauchn. Tsentra Ross. Akad. Nauk 131126 (2011)

89. Kondepudi B, Prigogine I Modern Thermodynamics. From Heat Engines to Dissipative Structures (New York: John Wiley, 1998); Translated into Russian: Sovremennaya Termodinamika. Ot Teplovykh Dvigatelei do Dissipativnykh Struktur (Moscow: Mir, 2002)

90. Baranovs'kii D M Vost.-Evrop. Zh. Peredovykh Tekhnol. 3928 (2009)

91. Bershadskiy L I Frict. Wear 81077 (1992)

92. Bhushan B, Nosonovsky M Acta Mater. 514331 (2003)

93. Aksenov I I, Strel'nitskii E E, in Tonkie Plenki v Elektronike. Dokl. 12-go Mezhdunar. Simpoziuma, 23-27 Aprelya 2001 (Thin Films in Electronics. Reports of the 12th Intern. Symp., 23-27 April 2001) (Eds A F Belyanina et al.) (Khar'kov: NNTs KhFTI, 2001) p. 96

94. Robertson J Surf. Coat. Technol. 50185 (1992)

95. Wei Q, Narayan J Int. Mater. Rev. 45133 (2000)

96. Donnet C Surf. Coat. Technol. 80151 (1996)

97. Hilton M R, Bauer R, Fleischauer P D Thin Solid Films 18819 (1990)

98. Scharf T W et al. Acta Mater. 544731 (2006)

99. Mitterer C Intermetallics 12579 (2004)

100. Turutoglu T Key Eng. Mater. 264-268 489 (2004)

101. Gulbinski W, Suszko T Surf. Coat. Technol. 2011469 (2006)

102. Köestenbauer H et al. Tribol. Lett. 3053 (2008)

103. Stone D S et al. Surf. Coat. Technol. 217140 (2013)

104. Kutschej K Adv. Eng. Mater. 81125 (2006)

105. Mulligan C P, Blanchet T A, Gall D Surf. Coat. Technol. 2041388 (2010)

106. Aouadi S M et al. Surf. Coat. Technol. 201418 (2006)

107. Aouadi S M et al. Acta Mater. 585326 (2010)

108. Basnyat B et al. Surf. Coat. Technol. 2021011 (2007)

109. Zhang Z, Dong H Manufact. Rev. 124 (2014)

110. Kelly P J et al. Surf. Coat. Technol. 2051606 (2010)

111. Muratore C et al. Surf. Coat. Technol. 2001549 (2005)

112. Hu J J, Muratore C, Voevodin A A Composit. Sci. Technol. 67336 (2007)

113. Adams D, Malgas G F, Theodore N D J. Vac. Sci. Technol. B 22 2345 (2004)

114. Chen L et al. Mater. Chem. Phys. 76224 (2002)

115. Aouadi S M et al. Surf. Coat. Technol. 2031304 (2009)

116. Voevodin A A, Bultman J E, Zabinski J S Surf. Coat. Technol. 107 12 (1998)

117. Voevodin A A et al. Surf. Coat. Technol. 76534 (1995)

118. Voevodin A A et al. Surf. Coat. Technol. 146351 (2001)

119. Baker C C, Hu J J, Voevodin A A Surf. Coat. Technol. 2014224 (2006)

120. Eklund P et al. Thin Solid Films 5181851 (2010)

121. Wang S et al. Tribol. Inter. 103228 (2016)

122. Dang W et al. Tribol. Inter. 104294 (2016)

123. Berger O et al. Thin Solid Films 5806 (2015)

124. Wang S et al. Mater. Des. 67188 (2015)

125. Huang Z et al. Ceram. Inter. 413701 (2015)

126. $\mathrm{Xu} \mathrm{Z}$ et al. Tribol. Lett. 53617 (2014)

127. Gupta S et al. Wear. 264270 (2008) 
128. Ma J et al. Tribol. Lett. 50323 (2013)

129. Rester M et al. Mater. Sci. Eng. A 42990 (2006)

130. Hopfeld M et al. Surf. Coat. Technol. 257286 (2014)

131. Emmerlich J et al. Wear 264914 (2008)

132. Liu Y, Chena J, Zhoua Y J. Eur. Ceram. Soc. 293379 (2009)

133. Hu C et al. J. Am. Ceram. Soc. 893456 (2006)

134. Gupta S et al. Wear 2621479 (2007)

135. Gupta S, Filimonov D, Zaitsev V Wear 2671490 (2009)

136. Ma J et al. Wear 297824 (2013)

137. Pogrebnjak A D et al. Vacuum 1 S235 (2009)

138. Koltunowicz T N et al. Acta Phys. Polon. A 123932 (2013)

139. Zukowski P et al. Phys. Status Solidi A 157373 (1996)

140. Pogrebnjak A D et al. Acta Phys. Polon. A 12094 (2011)

141. Komarov A F, Komarov F F, Żukowski P Vacuum 63495 (2001)

142. Pogrebnjak O D, Dyadyura K O, Gaponova O P Metallofiz. Noveishie Tekhnol. 37899 (2015)

143. Pogrebnjak A D et al. Phys. Usp. 55270 (2012); Usp. Fiz. Nauk 182 287 (2012)

144. Pogrebnjak A D et al. Russ. Chem. Rev. 831027 (2014); Usp. Khim. 831027 (2014)

145. Pshyk A V et al. Mater. Des. 94230 (2016)

146. Pogrebnjak A D et al. Tech. Phys. Lett. 411054 (2015); Pis'ma Zh. Tekh. Fiz. 41 (21) 66 (2014)

147. Wu Z et al. Tribol. Int. 94176 (2016)

148. Polcar T, Cavaleiro A Surf. Coat. Technol. 206686 (2011)

149. Chauhan K V, Rawal S K Proc. Technol. 14430 (2014)

150. Hogmark S, Jacobson S, Larsson M Wear 24620 (2000)

151. Nohava J, Dessarzin P, Karvankova P Tribol. Int. 81231 (2015)

152. Shtansky D V, Sheveyko A N, Sorokin D I Surf. Coat. Technol. 202 5953 (2008)

153. Yate L et al. RSC Adv. 461355 (2014)

154. Yate L et al. ACS Appl. Mater. Int. 76351 (2015)

155. Piedrahita W F et al. Surf. Coat. Technol. 286251 (2016)

156. Bull S J et al. Surf. Coat. Technol. 917 (1997)

157. Bull S J Tribol. Int. 30491 (1997)

158. Pogrebnyak A D et al. Tech. Phys. Lett. 39189 (2013); Pis'ma Zh. Tekh. Fiz. 39 (4) 9 (2013)

159. Shi J et al. Appl. Surf. Sci. 2589642 (2012)

160. Feng C et al. Appl. Surf. Sci. 320689 (2014)

161. Fox-Rabinovich G S et al. Sci. Technol. Adv. Mater. 13043001 (2012)

162. Yau B-S, Huang J-L, Lu H-H, Sajgalik P Surf. Coat. Technol. 194 119 (2005)

163. Lyashenko I A, Khomenko A V, Zaskoka A M Tribol. Trans. 56 1019 (2013)

164. Khomenko A V, Lyashenko I A Phys. Usp. 551008 (2012); Usp. Fiz. Nauk 1821081 (2012)

165. Fedotov A K et al. Mater. Chem. Phys. 177413 (2016)

166. Pogrebnjak A D et al. J. Alloys Compounds 679155 (2016)

167. Bagdasar'yan A A et al. Zh. Nano-Elektron. Fiz. 602028 (2014)

168. Pogrebnjak A D, Lebed A G, Ivanov Yu F Vacuum 63483 (2001)

169. Kumar $\mathrm{N}$ et al. Cryst. Res. Technol. 4553 (2010)

170. Koltunowicz T N J. Mater. Sci. Mater. Electron. 26 (9) 6450 (2015)

171. Koltunowicz T N et al. J. Electron. Mater. 44 (7) 2260 (2015)

172. Zukowski P et al. J. Alloys Compounds 68362 (2016)

173. Pshyk A V et al. Surf. Coat. Technol. 30549 (2016)

174. Pogrebnjak A et al. Ceram. Int. 4211743 (2016)

175. Pogrebnjak A et al. Ceram. Int. 43771 (2017)

176. Bazhin A I et al. Phys. Met. Metallogr. 117594 (2016); Fiz. Met. Metalloved. 117615 (2016)

177. Pogrebnjak A et al. Protect. Met. Phys. Chem. Surf. 52802 (2016)

Adaptive multicomponent nanocomposite coatings in surface engineering [Текст] / A.D. Pogrebnjak, A.A. Bagdasaryan, A. Pshyk, K. Dyadyura // Physics Uspekhi — 2017. — №60(6). 